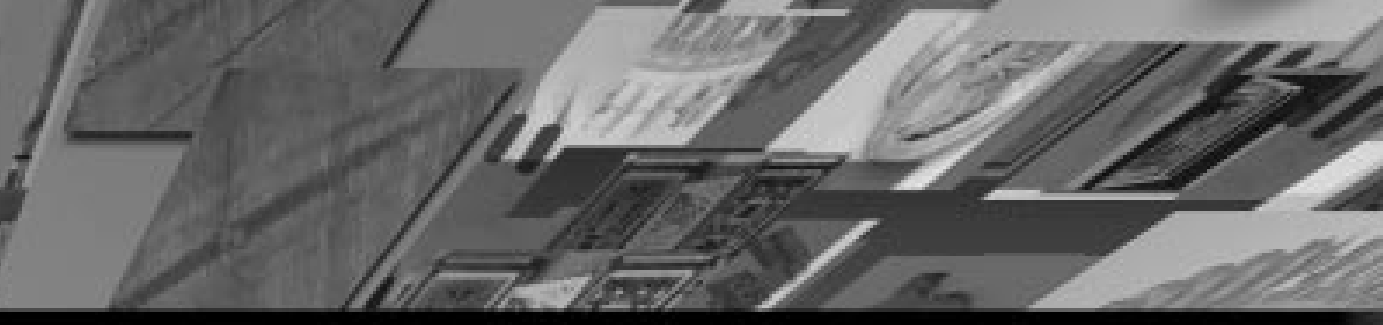

THRUST AREA REPORT • UCRL-ID-125475

\title{
Power Conversion Technologies
}

\section{Mark A. Newton, Thrust Area Leader}

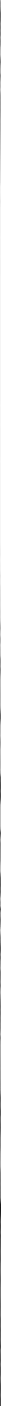

121 Ch is an info hal report intended primarily for internal or limited external alstintution. The opinions and conclusions stated are those of the author and

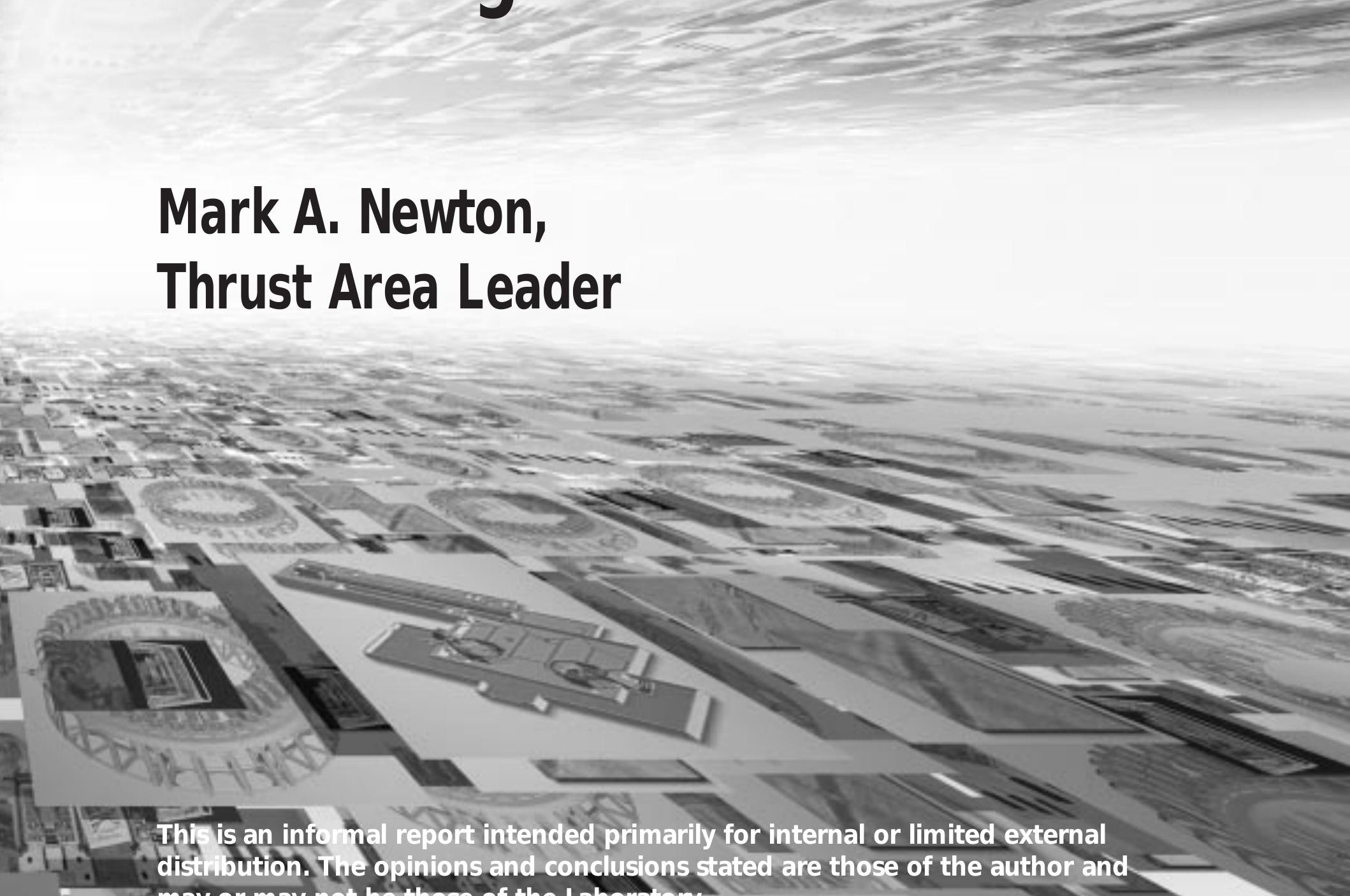
1 may or may not be those of the Laboratory.
Work performed under the auspices of the U.S. Department of Energy by Lawrence Livermore National Laboratory under Contract W-74,05-Eng-48.

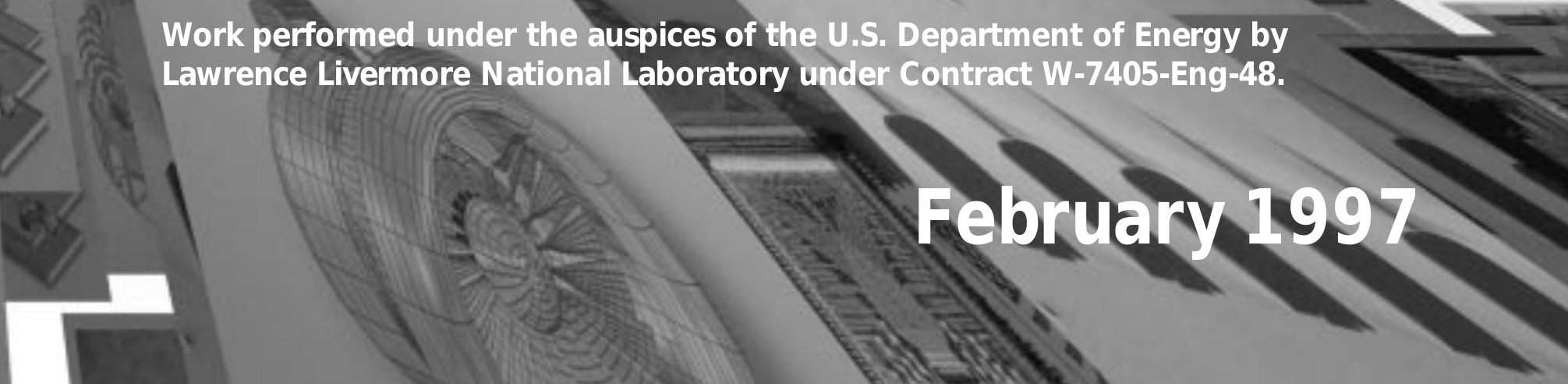




\section{Disclaimer}

This document was prepared as an account of work sponsored by an agency of the United States Government. Neither the United States Government nor the University of California nor any of their employees, makes any warranty, express or implied, or assumes any legal liability or responsibility for the accuracy, completeness, or usefulness of any information, apparatus, product, or process disclosed, or represents that its use would not infringe privately owned rights. Reference herein to any specific commercial products, process, or service by trade name, trademark, manufacturer, or otherwise does not necessarily constitute or imply its endorsement, recommendation, or favoring by the United States Government or the University of California. The views and opinions of authors expressed herein do not necessarily state or reflect those of the United States Government or the University of California, and shall not be used for advertising or product endorsement purposes.

This report has been reproduced

directly from the best available copy.

Available to DOE and DOE contractors from the

Office of Scientific and Technical Information

P.O. Box 62, Oak Ridge, TN 37831

Prices available from (615) 576-8401, FTS 626-8401

Available to the public from the

National Technical Information Service

U.S. Department of Commerce

5285 Port Royal Rd.,

Springfield, VA 22161 


\section{Power Conversion Technologies}

\section{Mark A. Newton, Thrust Area Leader}

Reprinted from Engineering Research, Development and Technology FY 96 UCRL 53868-96 


\section{Mark A. Newton, Thrust Area Leader}

The Power Conversion Technologies thrust area identifies and sponsors development activities that enhance the capabilities of engineering at Lawrence Livermore National Laboratory (LLNL) in the area of solid-state power electronics.

Our primary objective is to be a resource to existing and emerging $L L N L$ programs that require advanced solid-state power electronic technologies. Our focus is on developing and integrating technologies that will significantly impact the capability, size, cost, and reliability of future power electronic systems.

During FY-96, we concentrated our research efforts on the areas of (1) Micropower Impulse Radar (MIR); (2) novel solid-state opening switches; (3) advanced modulator technology for accelerators; (4) compact accelerators; and (5) compact pulse generators. 


\section{Power Conversion Technologies}

11

$\frac{11}{10}$

1. :5. Hhl 


\section{Power Conversion Technologies}

\section{Overview}

Mark A. Newton, Thrust Area Leader

Advanced Modulator Technology for Heavy Ion Recirculators

Roy L. Hanks, Hugh C. Kirbie, and Mark A. Newton .....

Evaluation of a Compact High-Voltage Power Supply Concept

Robert L. Druce, Randall E. Kamm, and Roy L. Hanks...

Millimeter-wave Microradar Development

Stephen G. Azevedo, Thomas E. MCE wan, and J ohn P. Warhus

High-Performance Insulator Structures for Accelerator Applications

Stephen E. Sampayan, David O. Trimble, George J. Caporaso, Yu-Jiuan Chen,

Clifford L. Holmes, Robert D. Stoddard, Ted F. Wieskamp, M. L. Krogh, and S. C. Davis.

\section{Compact Gas Switch Development}

David A. Goerz, Michael J. Wilson, Ronnie D. Speer, and J oseph P. Penland 


\title{
A dvanced Modulator Technology for Heavy lon Recirculators
}

\author{
Roy L. Hanks, Hugh C. Kirbie, and Mark A. Newton \\ Laser Engineering Division \\ Electronics Engineering
}

At Lawrence Livermore National Laboratory (LLNL) we are building a small-scale recirculator to demonstrate the feasibility of accelerating ions in a closed circular path. This report describes progress made in the development of a new solid-state induction modulator cell that is a key element in this effort.

\section{Introduction}

Recirculating induction accelerators are being investigated as potential low-cost drivers for inertial fusion energy. 1,2 A recirculator is a circular induction accelerator where beams of heavy ions are accelerated and deflected in a closed path, as illustrated in Fig. 1. Unlike linear machines, the acceleration sequence reuses each induction accelerating cell many times to reduce cost.

The Heavy Ion Fusion (HIF) project at LLNL is constructing a small recirculator that will demonstrate concept feasibility. This small-scale recirculator is a $4.5-\mathrm{m}$ diameter ring that will accelerate

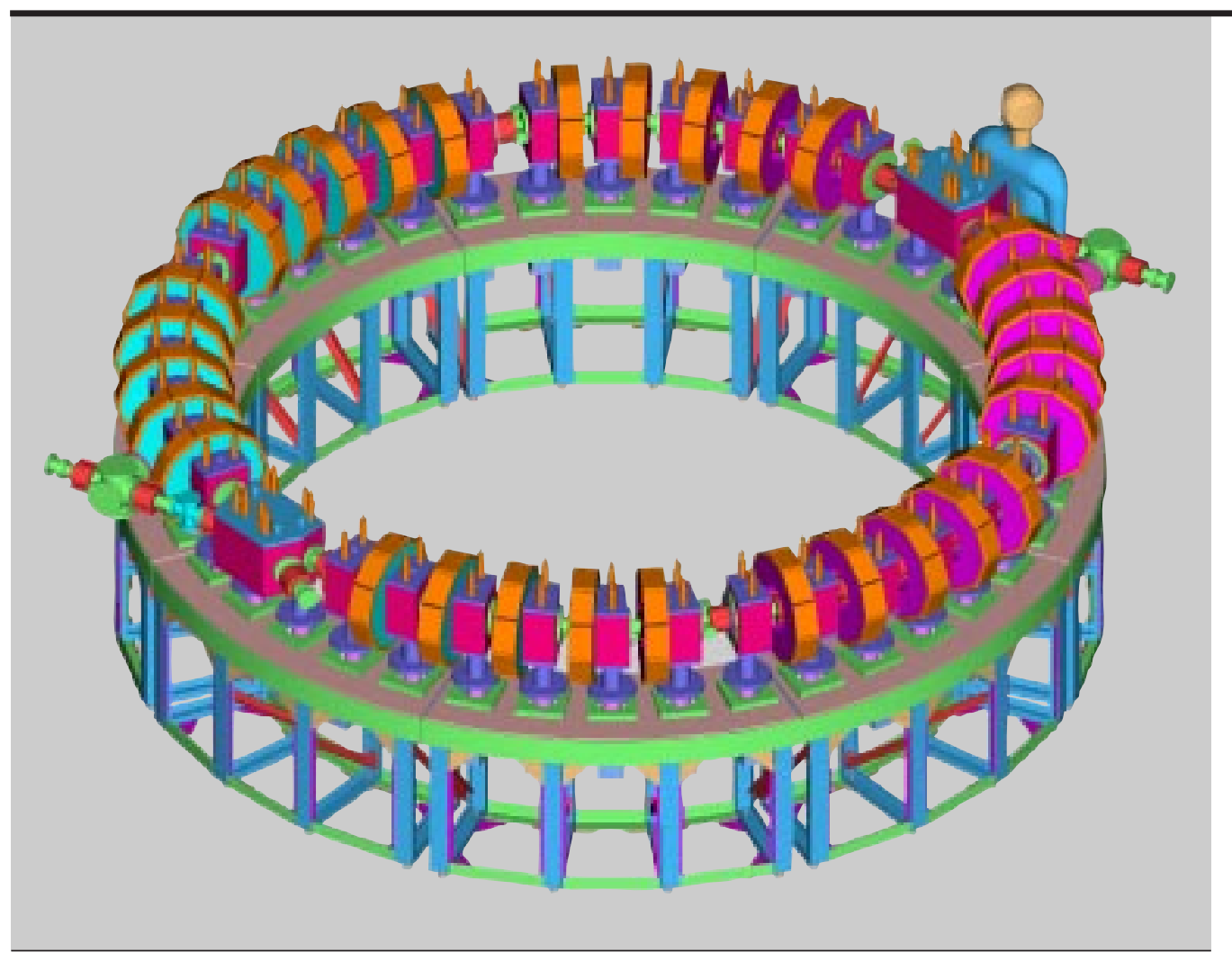

Figure 1.

Demonstration recirculator under construction at LLNL. 
singly ionized potassium ions to $320 \mathrm{keV}$, after 15 laps past the 34 induction accelerating cells that make up the ring.

\section{Electrical Requirements}

A sequence of pulses must be generated by each of the 34 modulators to accelerate the beam on each lap around the recirculator. The time between

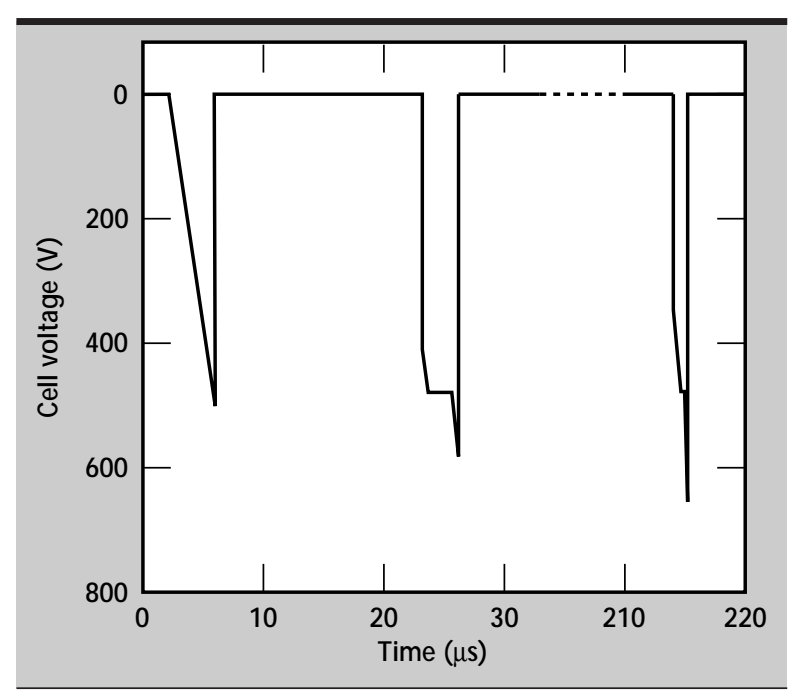

Figure 2. Simulation of a typical recirculator pulse schedule showing that each lap has a different pulse requirement. Notice a time-scale change after $30 \mu \mathrm{s}$, which eliminates 12 pulses from view. pulses is equal to the time it takes for the beam to make one full circuit of the ring. As the beam energy increases, the lap time decreases from $25 \mu \mathrm{s}$ to $10 \mu \mathrm{s}$, which corresponds to pulse repetition rates from 40 to $100 \mathrm{kHz}$.

Another facet of the recirculator experiments is the demonstration of longitudinal beam compression. As beam velocity increases and compression takes place, the modulator must generate pulses that reduce in width from 4 to $1 \mu \mathrm{s}$. To achieve compression of the ion beam, additional features are added to the modulator pulses. These features take the form of a variable risetime on the leading edge of the rectangular modulator pulses and a ramp that varies in amplitude and risetime appended to the trailing edge, as shown in Fig. 2. They have the effect of slowing down the head of the ion beam while speeding up the tail.

To meet these requirements, a system was proposed that uses two modulators within each induction cell. Their outputs are summed to achieve the desired voltage waveforms, as shown in Fig. 3. The first modulator produces the main $500-\mathrm{V}$ rectangular pulse that features risetimes of 250 ns to $1 \mu \mathrm{s}$, pulse widths of $1 \mu$ s to $3.5 \mu \mathrm{s}$, and pulse top regulation of better than $1 \%$. The second modulator generates a $30 \mathrm{~V}$ to $150 \mathrm{~V}$ ramp that modifies the trailing edge of the main pulse. This ramp varies in risetimes from 250 ns to $1 \mu s$ during the evolution of the pulse train.
Figure 3. Block diagram of induction cell.

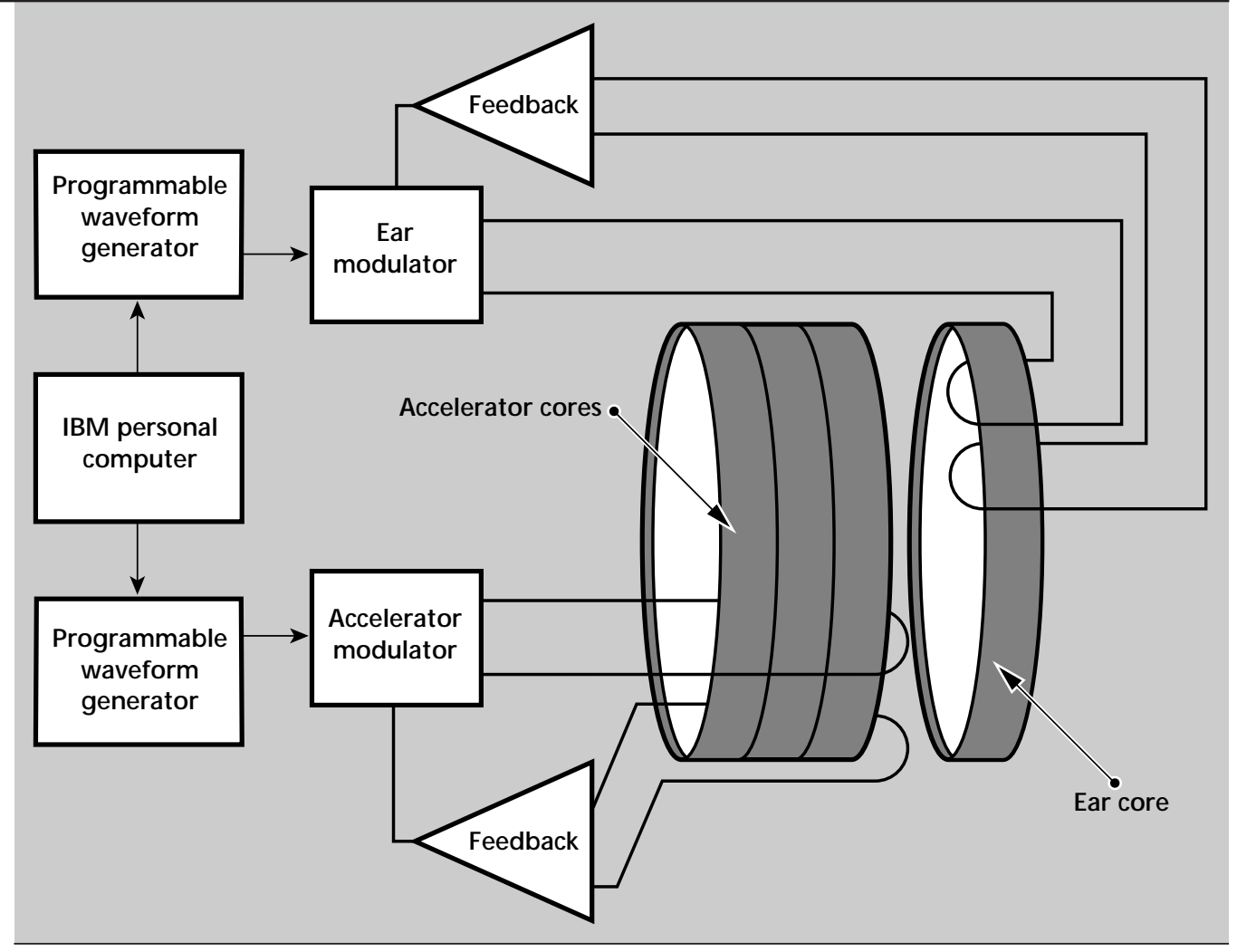




\section{Progress}

Initial evaluation of the main-pulse modulator was carried out with cores wound with Metglas $2605 \mathrm{CO}$. As a result of testing and research, it was determined that enhanced performance would be obtained with a new core of longitudinal field annealed Metglas 2605SC. This material promises to provide superior performance in terms of greater pulsed permeability and saturated flux density.

The ramp-generating modulator was first constructed using a single piece core of PE11B ferrite material. Early pulse tests indicated an unexpectedly low saturation flux density and permeability. We next wanted to evaluate the relative performance of CMD5005 ferrite material. Due to the large diameter of the toroidal core, a single piece unit was unavailable. The alternative was to purchase a core constructed of five epoxied

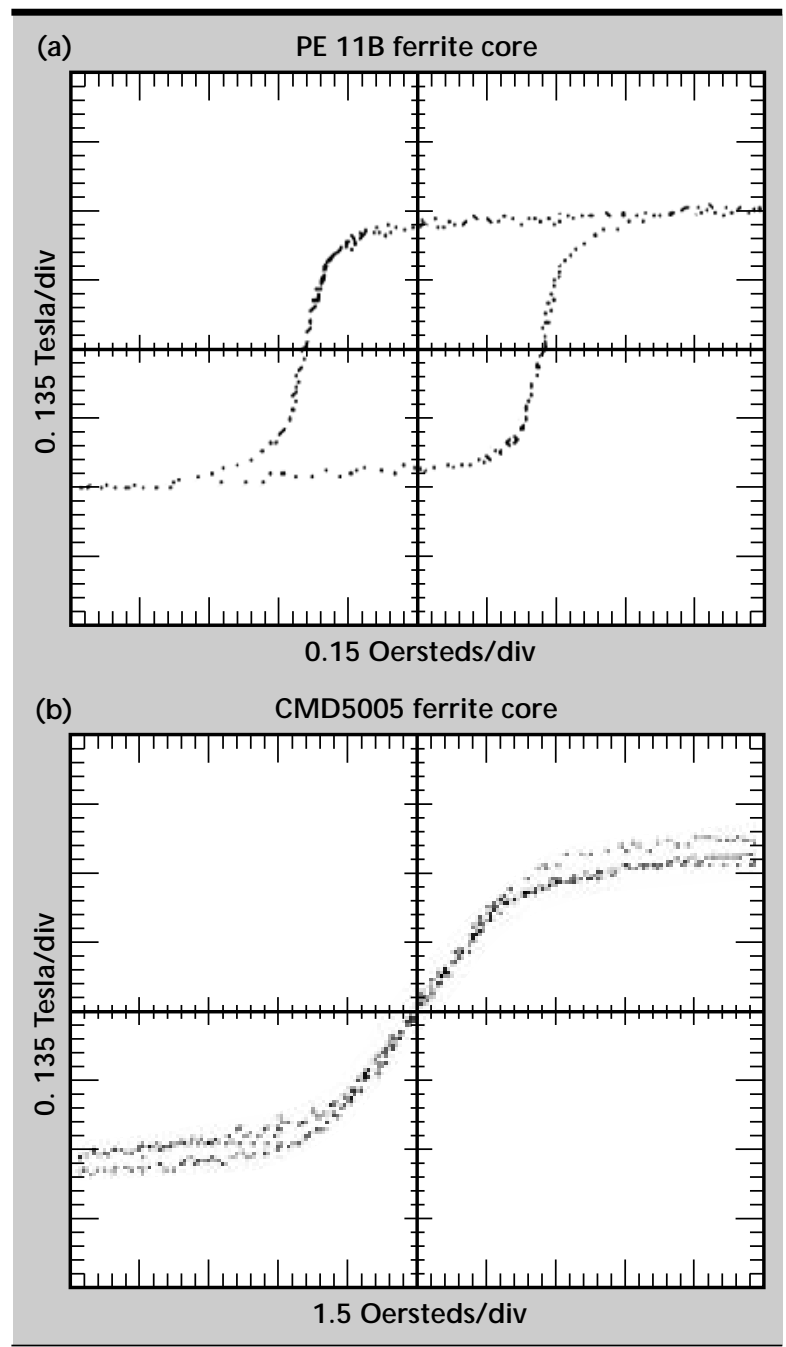

Figure 4. Low frequency B-H core mapping, revealing large differences in performance between PE11B ferrite (a) and CMD5005 segmented ferrite (b). segments. To better understand their magnetic properties, both cores underwent low frequency $\mathrm{B}-\mathrm{H}$ loop mapping. The test results, shown in Fig. 4, reveal substantial differences in the performance of the two ferrite materials.

From this data it was possible to determine the reason for the poor results encountered in the earlier pulsed PE11B core tests. Due to its "square" $\mathrm{B}-\mathrm{H}$ characteristics combined with incomplete electrical resetting, the core was allowed to operate over only a limited portion of the available B-H loop.

In contrast, the CMD5005 ferrite core behaved much like a gapped core inductor. We believe this is a direct result of its segmented construction, leading to no measurable residual flux density. This has the advantage of requiring only passive electrical resetting. On the negative side the permeability is also 20 times less than that of PE11B. Soon we will select the appropriate ferrite material and modify the ramp modulator to accommodate the choice. This decision will take into account parameters such as core size, transient response, electronic circuit complexity, and modulator cost.

The modulator electronics have undergone several revisions to drive and control circuitry over the past year. Here are a few examples:

1) Apex WB05 was replaced by the Elantec EL2008. The originally selected high-current buffer was costly and scheduled to be discontinued in 1997. It was replaced by a higher bandwidth driver for one tenth the cost.

2) Analog Devices AD840N was replaced by the National LM7171. The video op-amp that provides voltage regulation was upgraded in

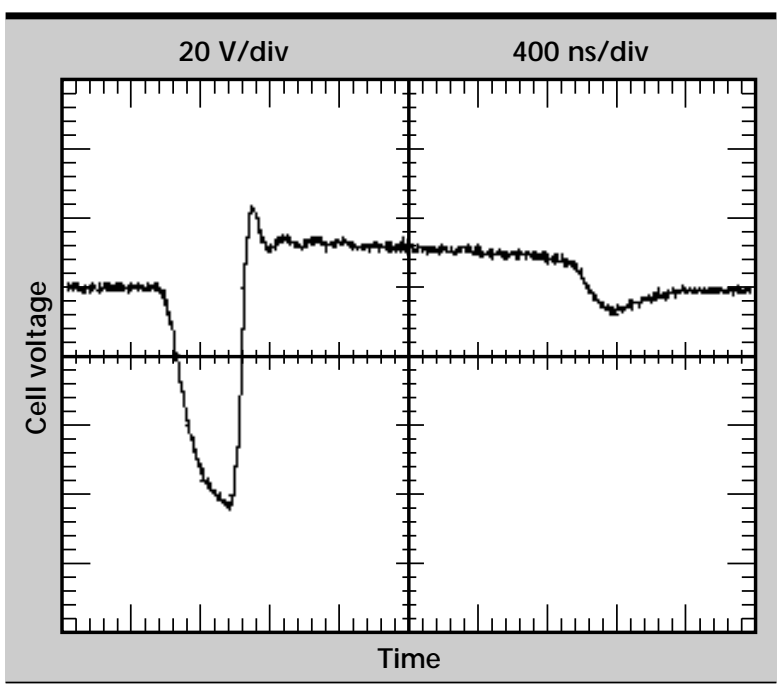

Figure 5. Typical ramp voltage waveform. 


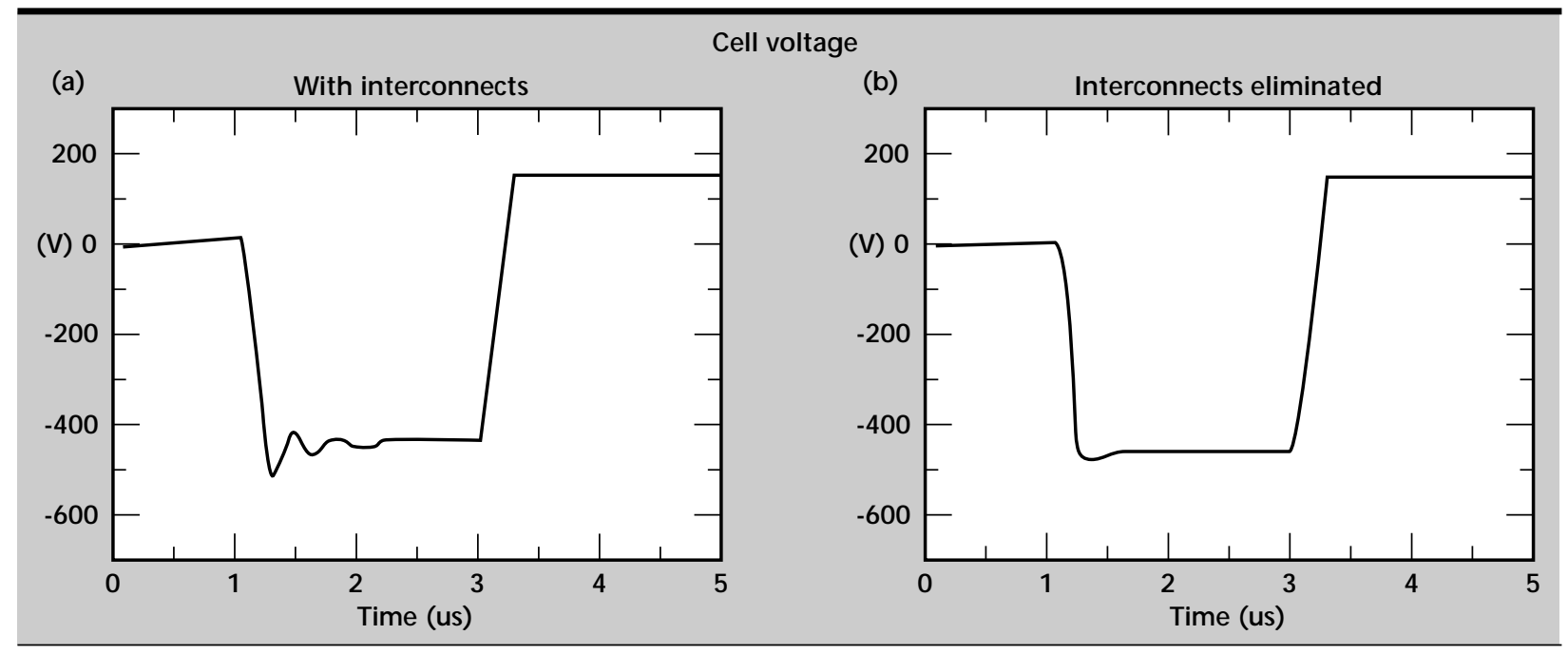

Figure 6. MicroCap IV simulations, showing a significant reduction in overshoot if interconnect inductance can be eliminated.

order to take advantage of the latest generation of high-speed/high-current op-amps with improved phase margin.

3) Many configurations of the voltage feedback network have been evaluated to meet the requirements of the induction cell and also to achieve the best balance of transient and DC regulation. Figure 5 shows a typical ramp voltage waveform using five voltage-regulated ramp modulators and a PE11B ferrite core.

4) The effect of stray inductance and capacitance on modulator performance was investigated. The primary stray circuit elements we considered have the form of package and interconnect inductance and stray capacitance that is attributed to the mechanical structure of the cell. Based on MicroCap IV simulations, a reduction in MOSFET gate inductance and interconnect lengths, shown in Fig. 6, could yield substantial performance improvements in the form of improved rise and falltime with less overshoot.

\section{Future Work}

As a result of the work that was conducted this past year two issues have come to light.

First, our present active reset circuit is not capable of determining if the core is initially at its positive or negative remanence state. This information is important to take advantage of the full core flux swings. The modulator circuitry will be revised such that the core will be initialized to the desired remanence state.

Second, our modulators are constructed using discrete component on printed circuit board technology. The next step is a collaboration with AlliedSignal on the design and construction of a hybrid microcircuit (HMC) that will increase packaging density and address the problem of stray and interconnect inductance. The first samples of these HMCs will be evaluated in FY-97. From these tests we hope to demonstrate the anticipated improvements in size and performance provided by this new technology.

\section{References}

1. Friedman, A., J. Barnard, M. Cable, D. Callahan, F. Deadrick, D. Grote, H. Kirbie, D. Longinotti, S. Lund, L. Nattrass, M. Nelson, M. Newton, C. Sangster, W. Sharp, T. Fessenden, D. J udd, and S. Yu (1995), "Progress Towards a Prototype Recirculating Induction Accelerator for Heavy-Ion Fusion," Proceedings of the 1995 Particle Accelerator Conference, Dallas, Tex., (UCRL-J C119538).

2. Newton, M., H. Kirbie, and R. Hanks (1995), Development of Advanced Modulator Technology for Heavy Ion Recirculators, Lawrence Livermore National Laboratory, Livermore, Calif., (UCRL 53868-95). 


\title{
valuation of a Compact High-Voltage Power Supply Concept
}

\author{
Robert L. Druce \\ Defense Sciences Engineering Division \\ Electronics Engineering
}

\author{
Randall E. Kamm and Roy L. Hanks \\ Laser Engineering Division \\ Electronics Engineering
}

We have evaluated a Russian-designed opening switch for use in a compact high-voltage power supply. The switch is for use in a charge-pump circuit which would eliminate the transformer while allowing the power supply to charge a capacitor to high voltage. The design parameters of the power supply were $<1.5 \mathrm{kV}$ input voltage, $100 \mathrm{kV}$ output voltage, $0.15 \mu \mathrm{F}$ load capacitor, and $<1 \mathrm{~s}$ charging time. The diode switches tested proved to be too lossy for this application. Additional evaluation is not planned for this concept unless devices with characteristics better suited to this application become available.

\section{Introduction}

High-voltage power supplies typically achieve voltage multiplication by means of a transformer. The size and weight of such power supplies are ultimately limited by the amount of wire in the transformer windings and the core material. Increased output voltage increases the number of turns necessary, while increased output power increases the size of the wire and amount of core material necessary. As a result, high power and high voltage conspire to increase the size and weight of the transformer and the power supply. Increasing the operating frequency improves conditions somewhat, but winding capacitance and switch speeds limit the possible improvement.

The design of high-voltage power supplies using transformer technology is a mature discipline, precluding major improvements in efficiency or size. Charging a capacitive load provides an additional challenge to the overall efficiency, since transformer-coupled supplies are constant-voltage sources in series with an impedance. A new, transformerless approach is required to provide additional significant reduction in size and weight of these supplies.

\section{Progress}

\section{Concept}

One possible alternative is a charge-pump circuit such as that shown in Fig. 1. This circuit uses an opening switch with an inductive store to pump small charge packets into the capacitive load. Since this circuit functions primarily as a constant-current source, the efficiency can be improved over that of a constant-voltage source supply for capacitor charging. The main challenge with this circuit is finding an appropriate opening switch to drive the inductive store. This switch must be capable of operating at the desired output voltage at a high repetition rate and must have low losses.

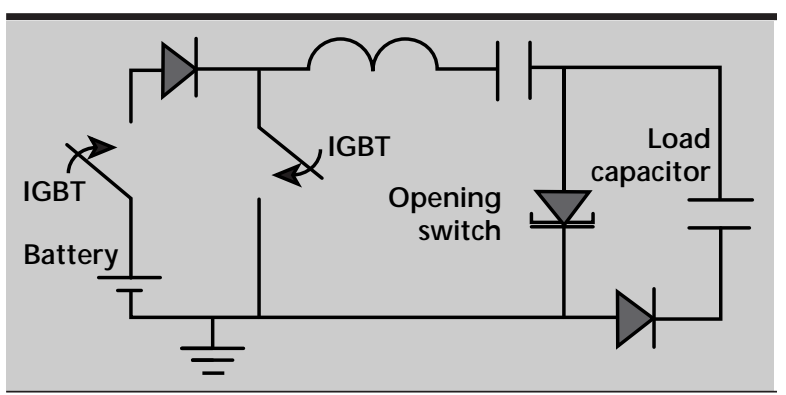

Figure 1. Simple charge-pump circuit using an opening switch for voltage multiplication. 


\section{Opening Switch}

The likeliest candidate for an opening switch in this application is a solid-state device. The switch chosen for evaluation is a diode of Russian design. This device consists of a series/parallel stack of diode junctions with each junction tailored to open at a very high rate after being biased with a specific waveform. The diode stacks are rated at $100 \mathrm{kV}$ opening voltage against $800 \mathrm{~A}$ current and $12 \mathrm{~ns}$ opening time. The stacks are about $10 \mathrm{~cm}$ long. The diodes must be driven with a ringing waveform to give the proper initial conditions for opening. These diodes are designed to be used as a pulse sharpening element. We planned to evaluate them in a somewhat different regime, giving rise to some risk.

\section{Diode Evaluation Circuit}

A schematic of the evaluation circuit is shown in Fig. 2. The circuit was fabricated using strip lines to give minimal parasitic circuit elements. The circuit parameters were varied over the range shown in Table 1 . The maximum voltage was limited to a range similar to that attainable by commercial solid-state closing switches since any practical power supply would use these devices. Operation of the circuit with no opening switch diode installed agreed with calculated waveforms to within a few percent.

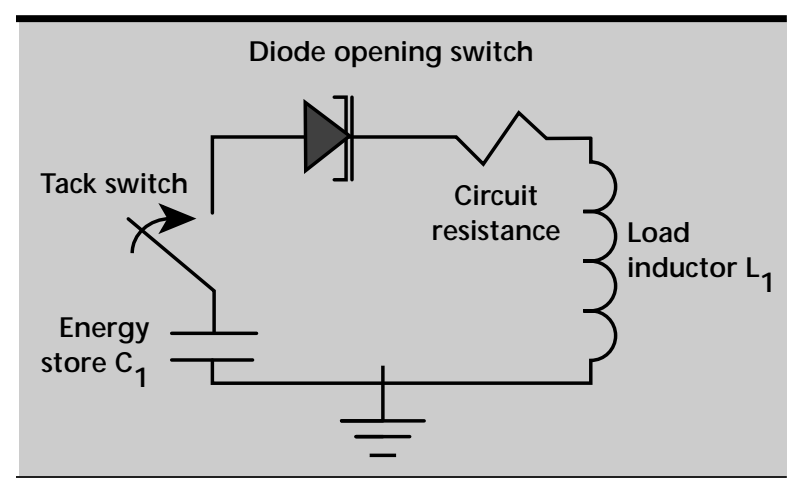

Figure 2. Schematic of the circuit used to evaluate the opening switch diodes. The switch is a solid-dielectric tack to give fast turn-on and low impedance over a wide range of voltage and current.

Table 1. List of circuit parameters and range of variation.

\begin{tabular}{ll}
\hline Circuit parameter & Range \\
\hline Source Capacitance $\left(\mathrm{C}_{1}\right)$ & $10-100 \mathrm{nF}$ \\
Circuit Inductance $\left(\mathrm{L}_{1}\right)$ & $1-10 \mu \mathrm{H}$ \\
Charge voltage & $100-2,400 \mathrm{~V}$ \\
\hline
\end{tabular}

\section{Diode Evaluation}

Initial DC evaluation showed a forward bias gap voltage of $\approx 85 \mathrm{~V}$ and a forward resistance of about $2 \Omega$. The DC small-signal reverse resistance indicated $\approx 10 \mathrm{M} \Omega$. The forward bias gap voltage was verified with the pulsed experiments but the forward impedance was not consistent and was possibly masked by other effects. No attempt was made to verify the reverse characteristics in the pulsed tests. The diodes showed a definite threshold current (and charge) for switching. Figure $\mathbf{3}$ shows a typical inductor voltage and current waveforms for a switching event. The parameters for this event were as follows: $V_{\text {chg }}=500 \mathrm{~V}, \mathrm{~L}=7.5 \mu \mathrm{H}$ and $\mathrm{C}=51 \mathrm{nF}$.

Note that the voltage of the inductor spikes up as the current falls when the diode switch opens. This event had a voltage gain of approximately 0.95 into an open circuit. The inductor voltage early in the waveform is approximately $200 \mathrm{~V}$. This leaves about a $300 \mathrm{~V}$ drop across the opening switch diode. Figure $\mathbf{4}$ is a plot of the same

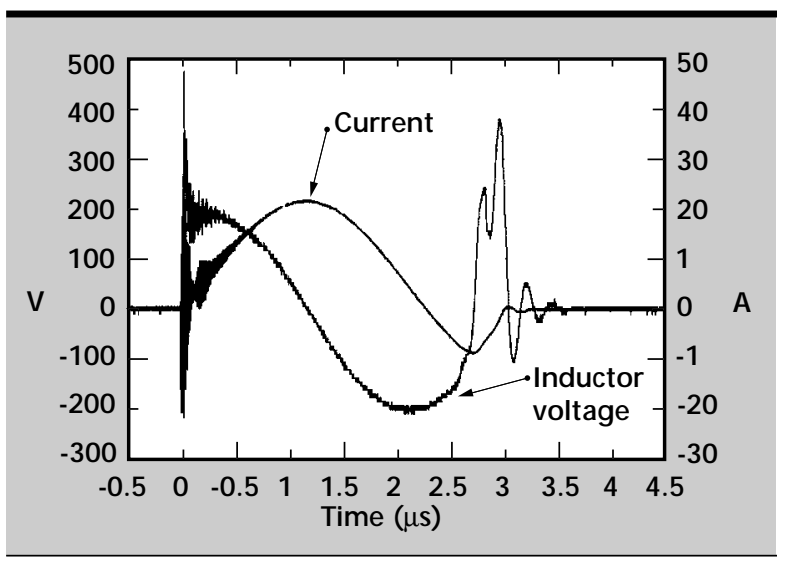

Figure 3. Plot of inductor voltage and total circuit current for a typical switching event. The parameters for this event were $\mathrm{V}_{\mathrm{chg}}=500 \mathrm{~V}, 7.5 \mu \mathrm{H}$ inductor and $51 \mathrm{nF}$ capacitor.

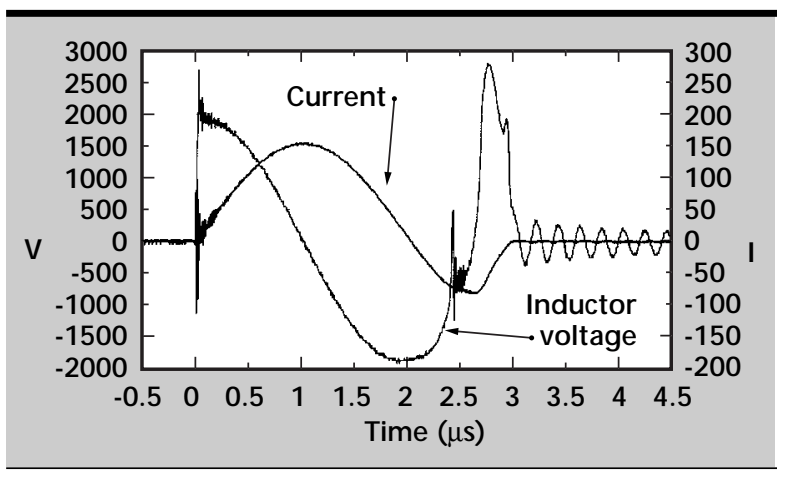

Figure 4. Plot of inductor voltage and circuit current. The charge voltage is $2400 \mathrm{~V}$ for this event. The circuit inductance is approximately $7.5 \mu \mathrm{H}$; the source capacitance is $51 \mathrm{nF}$. 


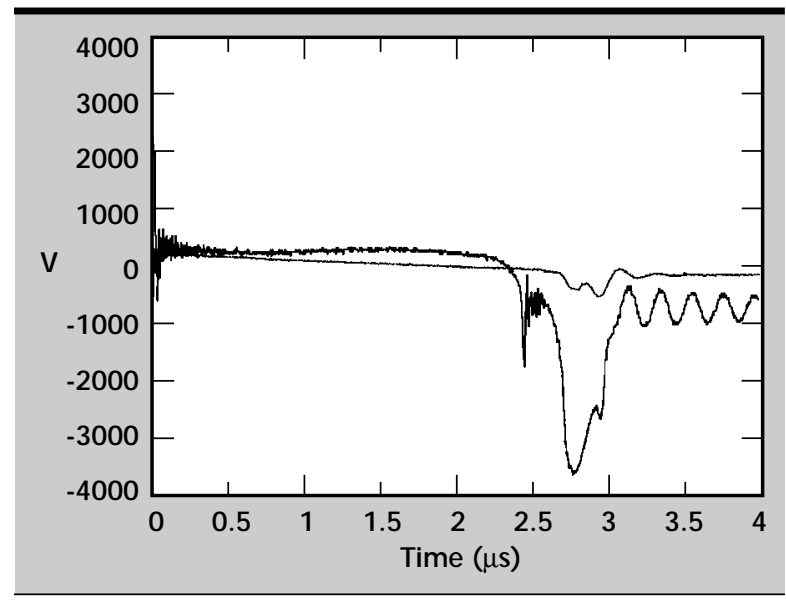

Figure 5. Comparison of the diode voltage for $500 \mathrm{~V}$ and $2400 \mathrm{~V}$ charge switching events. The waveform with the larger negative spike is the $2400 \mathrm{~V}$ charge waveform.

waveforms with a $2400 \mathrm{~V}$ charge and the same circuit parameters. The voltage gain is approximately 1.2. Note that the voltage gain is increasing with increasing voltage and current, indicating that the diodes will perform well at much higher voltage and current. Figure $\mathbf{5}$ is a comparison of the voltage across the diode for the same two switching events, showing that the diode is extremely lossy but that the losses are not linear with voltage or current. We have not been able to determine definitively the source of this loss.

These waveforms show typical behavior for the switch. The waveforms with differing capacitance and inductance in the circuit are similar. The gain is typically lower with less circuit inductance and small inductance showed a higher switching threshold.

\section{Conclusion}

Though the concept of a charge-pump high-voltage power supply is quite appealing, the new opening switch diode technology evaluated is not appropriate to produce the voltage gains needed in the parameter space required. These devices were evaluated in a regime that they were not specifically designed for, on the possibility that they would produce the necessary voltage gain. In light of the large gap between the required parameters and those demonstrated by the devices tested, we discontinued the investigations without extensive research into the nature of the losses in the devices.

The results of these investigations do not imply that the devices are not appropriate for pulse sharpening at higher voltage and current. 



\title{
illimeter-wave Microradar Development
}

\author{
Stephen G. Azevedo and Thomas E. McEwan \\ Laser Engineering Division \\ Electronics Engineering
}

\author{
John P. Warhus \\ Defense Sciences Engineering Division \\ Electronics Engineering
}

The objective of this project was to enhance the low-cost impulse radar systems made famous at the Lawrence Livermore National Laboratory ( $L L N L)$ with new ranges of frequency, resolution, and directionality. Moving into these ranges opens up many new areas of application while expanding our expertise in small low-power radar systems. Several areas were identified that are leading to projects in support of LLNL programs, as well as generating new outside funding. Small, low-cost radar systems enable many applications that use arrays of transmit/receive elements, and we are pursuing many such imaging system concepts.

\section{Introduction}

In a previous report, ${ }^{1}$ we described many of the different types of Micropower Impulse Radar (MIR) systems that have been developed in support of numerous government and commercial systems in the last few years. The main ideas behind MIR, invented by T. McEwan at LLNL, are the generation and detection systems for extremely low-power ultra-wideband pulses in the gigahertz regime using low-cost components. These ideas, coupled with new antenna systems, timing and radio-frequency (RF) circuitry, computer interfaces, and signal processing, have been the catalysts for a new generation of compact radar systems. The systems generally fall into four sensor categories: 1) motion sensors; 2) distance sensors; 3) imaging sensors; and 4) communication devices. (For more information on these systems, and on the overall MIR Project, see past reports ${ }^{2}$ or our world-wide web page at http://www-lasers.IInl.gov/lasers/idp/mir/ mir.html.)

There are still many new directions that we plan to explore, to continue our leadership role in MIR. Rather than repeat the broad list of sensors and systems within the MIR scope, in this report we will describe our efforts in FY-96 to develop higher performance (yet still small and low-cost) radars that will expand the technology base and offer more opportunities. As an entirely new technology area, rather than a single circuit, MIR has the potential to address a rich set of applications for which there is not yet program, government, or commercial support. The modular systems and higher-frequency sensors developed in the last year will inspire numerous novel concepts that have high expected impact and return on investment. We plan to embark on areas that will enhance our engineering expertise and technology base, while providing new opportunities and capabilities for programs.

\section{Progress}

The objective of this project was to expand and advance our current capabilities in MIR technology along several directions. We discuss the key technical MIR developments in terms of the technology improvements, with applications for each.

\section{Modular MIR Components}

In an effort to produce functional radar modules that can have many features to aid system development, we have designed and developed a family of MIR boards, antennas, interconnections and software with standard interfaces that "plug and play" 
together. Figure 1 is a schematic diagram of MIR modular components that fall into four general categories of software, computer interfaces, timing and baseband processing circuits, and high-speed front ends. The interconnections between the categories are based on industry standard hardware or software components (for example, SMA or audio connectors, $\Pi \mathrm{TL}$ voltages, and $50-\Omega$ terminating resistances).

The focus of our effort has been on the timing and high-speed circuitry, where much of the family has already been implemented. Incorporated into these modules are many of the anticipated enhancements needed to develop future MIR hardware systems. For this reason, the modular MIR boards are generally larger than the first generation of boards, but their layout is such that subcircuits can be easily reconfigured to build custom boards, or potentially application-specific integrated circuits (ASIC's), for particular applications. Both government and commercial projects are better served by the modular approach, because prototyping of radar systems becomes a simpler task and direct characterization of the individual components is more straight forward than with previous MIR systems.

Significant progress has been made in generating radar components that produce consistent and repeatable responses under most conditions. In contrast to earlier MIR prototypes, the current surface-mount board designs are very robust to shock, interference, and temperature changes. For example, a constant-fraction discriminator (CFD) has been added to the Dipstick and Rangefinder

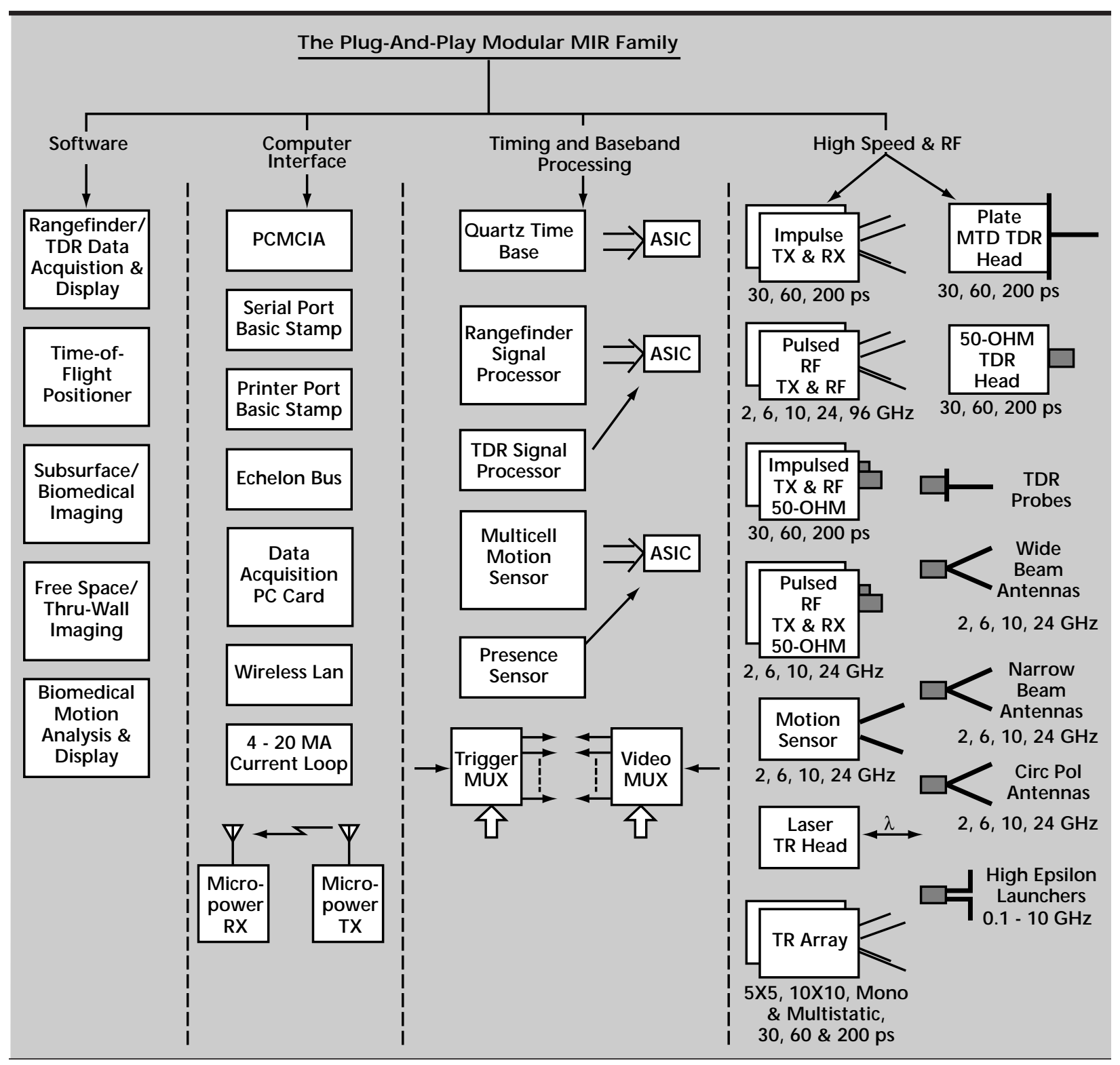

Figure 1. The MIR modular system. 
systems that automatically adjusts a threshold detector to a temperature-compensated reference voltage. Then distance or range is measured by pulse-width modulation of the time between threshold crossings of MIR impulses.

For a 100-ps-wide pulse, the leading edge risetime corresponds to about $1.5 \mathrm{~cm}$ in range. To hold range errors below $1 \mathrm{~mm}$, we need a threshold detection accuracy of better than $6 \%$, regardless of pulse amplitude. Compensation for voltage and thermal changes (about 1\% fluctuation over outdoor temperatures) is automatic and flexible enough to operate under harsh conditions.

Out of the modular components described in Fig. 1, there are several complete radar systems that have been developed in the last year.

1. MIR Motion Sensor. ${ }^{3}$ This is an enhanced version of the single-board motion sensor that can be easily reconfigured to match a specific need. Like the original, it is range-gated, low power (multi-year battery life), low cost, channelless (multiple MIR units can operate in close proximity without RF interference), and nearly impossible to detect. A photograph of the board with simple quarter-wave antennas is shown in Fig. 2.

Only motion-modulated signals or changes from a baseline measurement are detected, thereby eliminating false triggers from stationary room "clutter." The motion pass-band can be changed by modifying the on-board filter components to match the application. An independent laboratory has verified that the MIR motion sensor can satisfy FCC Part 15 regulations. Applications are in security and energy control systems, industrial safety, robotics, vibration sensing, and speech processing.

2. MIR Electronic Dipstick. ${ }^{4}$ This is a two-board low-cost time-domain reflectometer (TDR) system that was designed to detect the height of fluid in a reservoir or container by measuring the pulse-echo time of an MIR pulse launched along a transmission line-a simple wire. The two modular boards are the quartz time base and TDR signal processor described in Fig. 1. Measurement of the fluid height is typically resolved to $0.1 \%$ of maximum range. There are many applications of the system in measuring fluid and material levels in industrial containers (tanks, vats, silos), hazardous materials, downhole water levels, automotive tank monitoring, and in providing automatic fill control.

3. MIR Rangefinder. ${ }^{5}$ This is a five-board complete impulse radar transceiver system with swept range-gate and ultra-wideband antennas. A photograph of the full modular Rangefinder is shown in Fig. 3. The five boards used are the quartz time base, Rangefinder signal processor, 60-ps impulse receiver, and two transmitter boards (60-ps impulse and 6.5-MHz pulsed oscillator boards). The receiver works equally well with both impulse and pulsed-oscillating transmitters. Waveform outputs of the two transmitters are shown in Fig. 4. It generates an equivalent-time A-scan (echo amplitude vs range, similar to a WW-II radar) with a typical

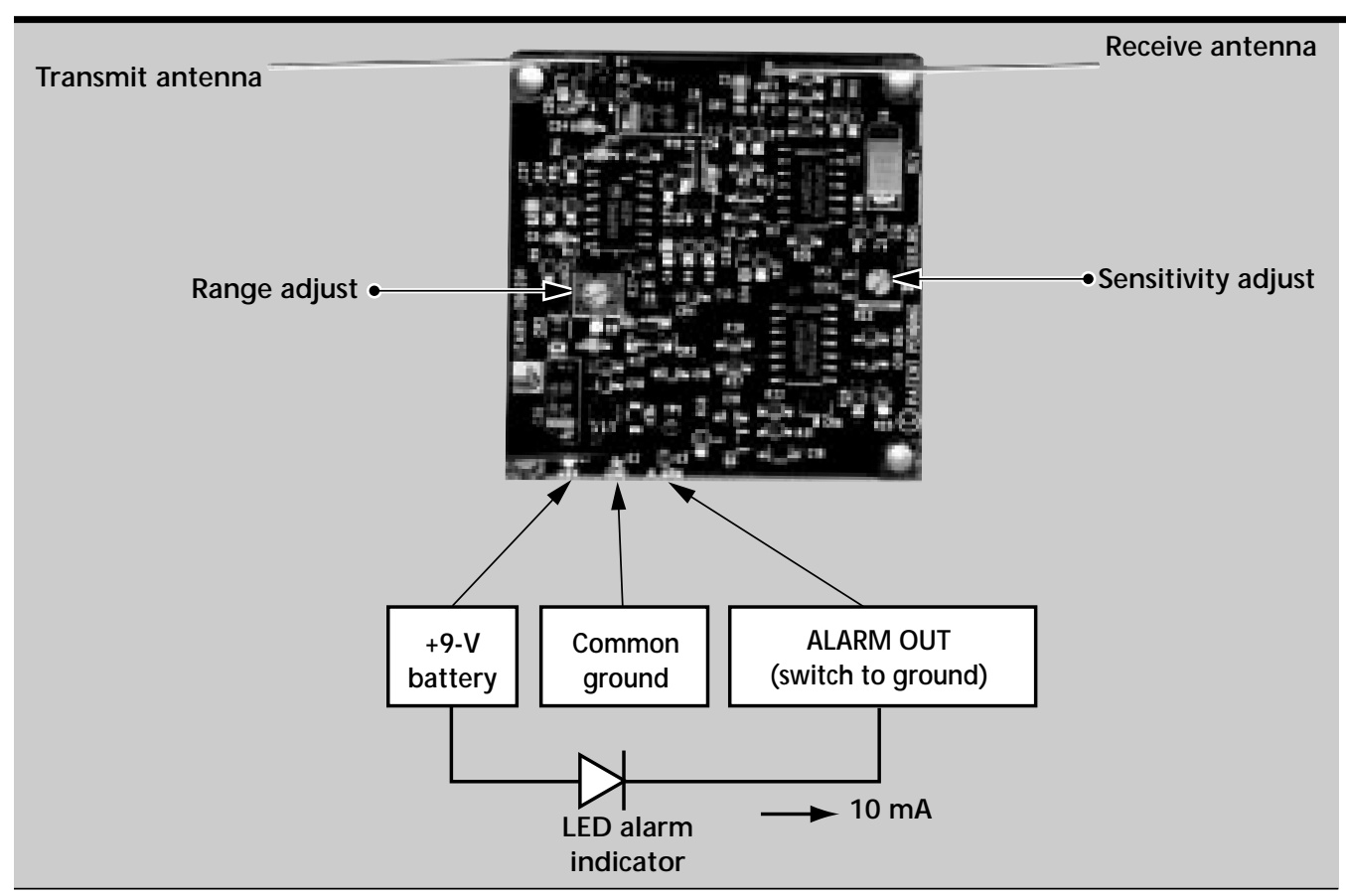

Figure 2.

Photograph of the MIR Motion Sensor with simple interconnects. 
range sweep of $10 \mathrm{~cm}$ to $3 \mathrm{~m}$, and an incremental range resolution, as limited by noise, of $0.3 \mathrm{~mm}$. It operates in spectral regions that readily penetrate walls, wood panels, and to an acceptable extent, concrete and human tissue.

The MIR Rangefinder is the most sophisticated of the dozens of MIR prototypes; it is the basis of all imaging applications and of many reimbursable projects. Uses of the Rangefinder include replacement of ultrasound rangefinders for fluid-level sensing (a dipstick without the stick), light-weight altimeters for unmanned airborne vehicles, localizing breathing motion behind walls, vehicle height sensing, and robotics control. When positioned over a highway lane, it can collect vehicle count, vehicle profile, and approximate speed data for traffic control.
Figure 3.

Photograph of the

Modular MIR

Rangefinder with

simple interconnects.

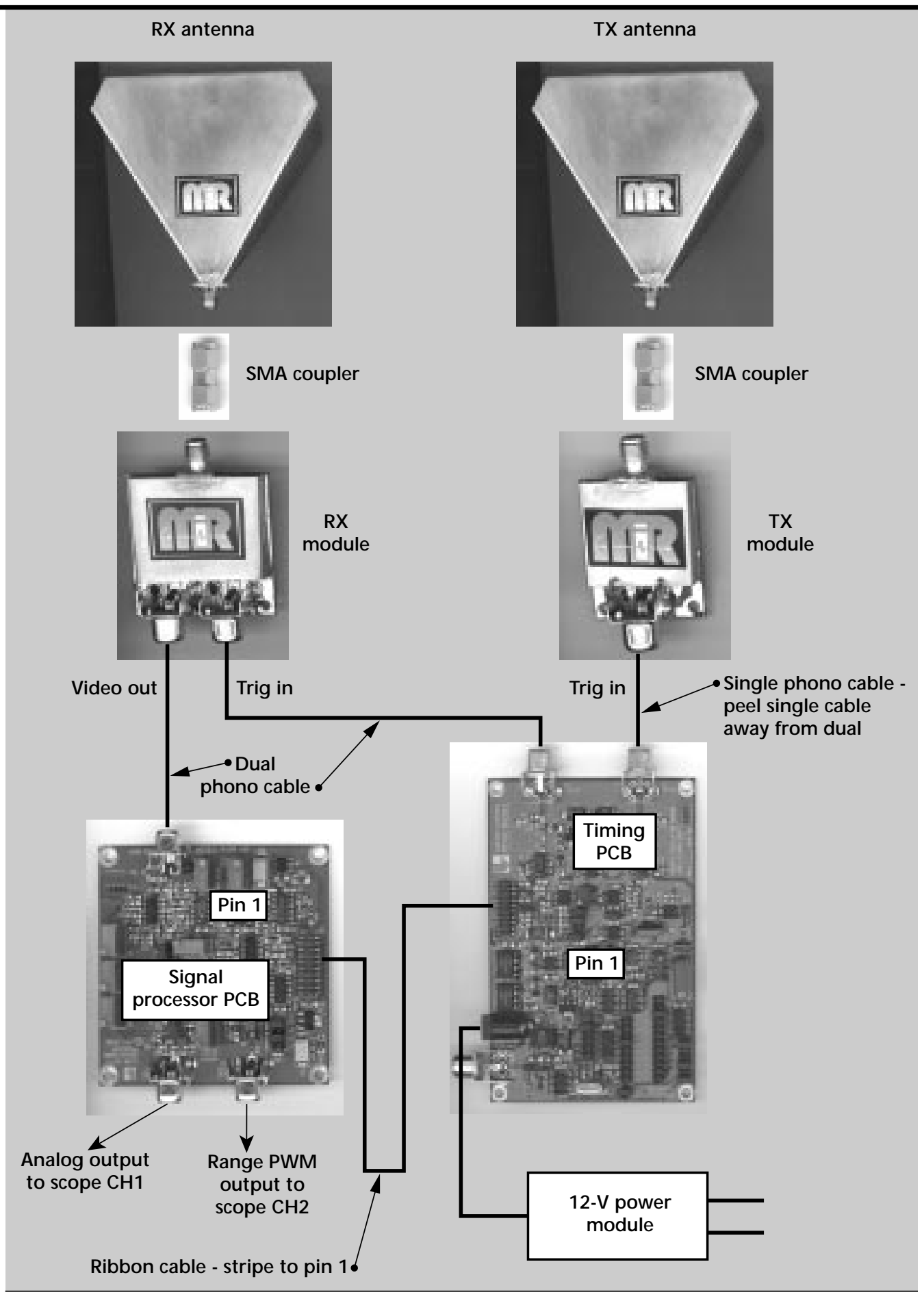




\section{Rangefinder Extensions}

As mentioned in the last section, the modular MIR architecture makes it possible to extend the Rangefinder to new levels of performance and capability. Where the original Rangefinder was a fullyintegrated unit with fixed antennas, the modular design adds flexibility to our prototyping efforts. During the development of the modular design, we also added improvements to the standard MIR features (without substantially adding to the cost). For example, the CFD described above is now directly integrated into the Rangefinder design. Also included are more accurate time-base generation $0.1 \%$ over the maximum range using a crystal oscillator), high- and low-frequency cut-off filter controls, and wide flexibility in the start location and length of the scan. In this section, we describe some additional extensions to the Rangefinder made possible by the plug-and-play concept.

The modular MIR Rangefinder provides the perfect vehicle for ultra-wideband imaging applications, and we are currently working on several such projects through outside sponsorship. Multiple transmit/receive modules (yet only one time base and one Rangefinder signal processor) can be configured into arrays of radars and coupled to a computer to form either synthetic aperture or realarray imaging. ${ }^{6}$ Radar return signals are digitized and stored in the computer. Reconstruction of cross-sectional images from B-scan or waterfall type data is performed by diffraction tomography software on the computer. ${ }^{7}$ Images of the scene are displayed directly on the screen within $10 \mathrm{~s}$ (in 2-D).

We have demonstrated the use of this radar package for integration into an imaging array that is small, lightweight, low power, and inexpensive, relative to existing radars. Some of the imaging applications we are exploring are road-bed and bridge-deck inspection, ${ }^{8}$ land mine and buried ordnance detection, ${ }^{9,10}$ detection of underground utility lines, through-wall detection of people (for military, law enforcement, and search and rescue teams), and nondestructive evaluation (NDE) of concrete (civil structures, earthquake damage), wood (lumber evaluation, power pole rot), or, to a limited extent, living tissue (hematoma detection, kidney stones). Other materials are also possible candidates for material inspection, such as low density foams and composites.

The current arrays use monostatic imaging, but future versions will be capable of multistatic operation. The modular system makes it possible to separate the antennas to any distance and to perform both reflection and transmission experiments. In conjunction with the NDE Thrust Area, we are developing systems to explore these and other possibilities (see the article by J. Mast, in the NDE section of this report).

For the bridge-deck inspection project, ${ }^{8}$ a highspeed radar (HSR) front-end system was developed that requires single pulse detection with no averaging so that the vehicle can travel at highway velocities and still detect subsurface flaws. While still small, the HSR has higher performance specifications (with associated higher cost and higher power) than its MIR counterpart. However, the HSR frontend hardware was made so that it attaches to the modular MIR antennas and back-end circuitry as another module to the tool set. This is another example of how all applications can now fit the common architecture.

\section{Antennas}

It will be necessary to integrate the electronics with the antennas in future versions of the imaging radar systems. This is needed to keep the

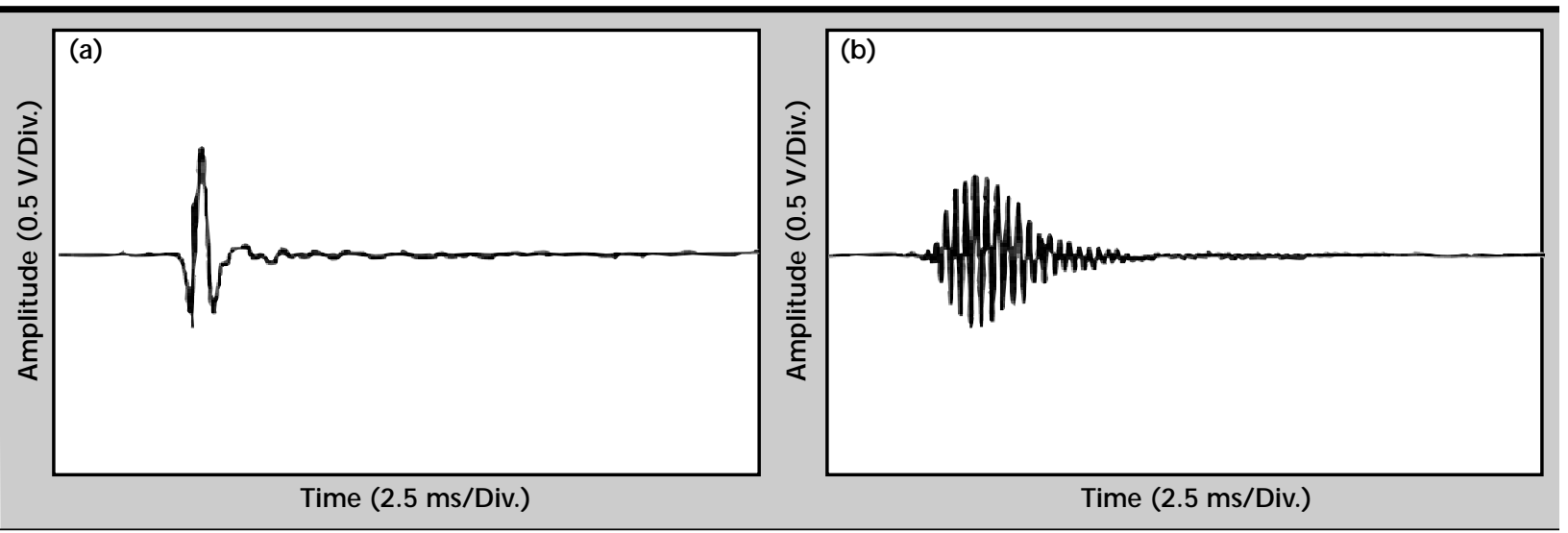

Figure 4. Video output of the MIR Rangefinder using the impulse transmitter (a) and the pulsed-oscillating transmitter (b). The transmitting and receiving antennas are pointed directly toward one another with about $20 \mathrm{~cm}$ stand-off. 
electronics small, robust, and fast. Integrated electronics of this type will advance our capabilities in radar well beyond the current state of the art, and open numerous new areas of program development. Higher power and other directional imaging arrays may also be required for specific applications. A list of antenna constraints for the MIR Rangefinder may include:

1) $s_{11}$ and $s_{21}$ characteristics that are flat across a very broad band and exhibit smooth, linear phase $s_{21}$ roll-off at the band edges;

2 ) group delay ( $d \Phi / d f)$ substantially less than the impulse width across the operating band, such as less than 50 ps across 1 to $10 \mathrm{GHz}$ (equivalently, very clean step function response);

3 ) well-controlled, low sidelobes - no change in pulse shape vs angle;

4) Iow feedline-coupling into the antenna; and

5) low-cost, compact, rugged, and simple construction.

In conjunction with the Computational Electronics and Electromagnetics Thrust Area, a significant amount of effort has been directed toward stable, repeatable, and scaleable ultra-wideband antenna designs. This work has been instrumental in improving the beam-width, bandwidth, impedance, launch point, size, shape, and crosstalk characteristics of the complete MIR system. Several antenna designs are currently being used and are pending patent consideration. The basic imaging antennas have a very broad beam width and correspondingly low gain. They are suitable for synthetic aperture imaging where broad illumination is desirable. Narrower beam widths and higher gain can be obtained on a broadband basis with horns, reflectors, or dielectric lenses.

\section{Frequency Extensions}

Extending the frequency range of MIR from the maximum of about $4 \mathrm{GHz}$ (microwave) into the millimeter-wave bands has been initiated in the last year. We have accomplished this with both impulse systems (wideband up to $12 \mathrm{GHz}$ ) and pulse-driven oscillators (at $20 \mathrm{GHz}$ and $94 \mathrm{GHz}$ ). Figure 5 shows the relationships of frequency range to resolution and penetration depth. By going to higher frequencies, wavelengths become shorter, antennas become smaller, and resolution improves to the millimeter range. Pulses at these higher frequencies can be launched more directionally and with lower sidebands. Penetration into materials is much less, but the resolution (on the order of $1 / 4$ wavelength) is much greater. Also, for most applications the pulse will be launched in air, where losses are small. In all cases, we use the modular MIR timing and video processing on the back end while emphasizing research in the pulse driver circuitry.

An important advantage of moving into the millimeter-wave bands is that very high-gain antennas can be designed, which are small when compared to antennas with similar gain in the

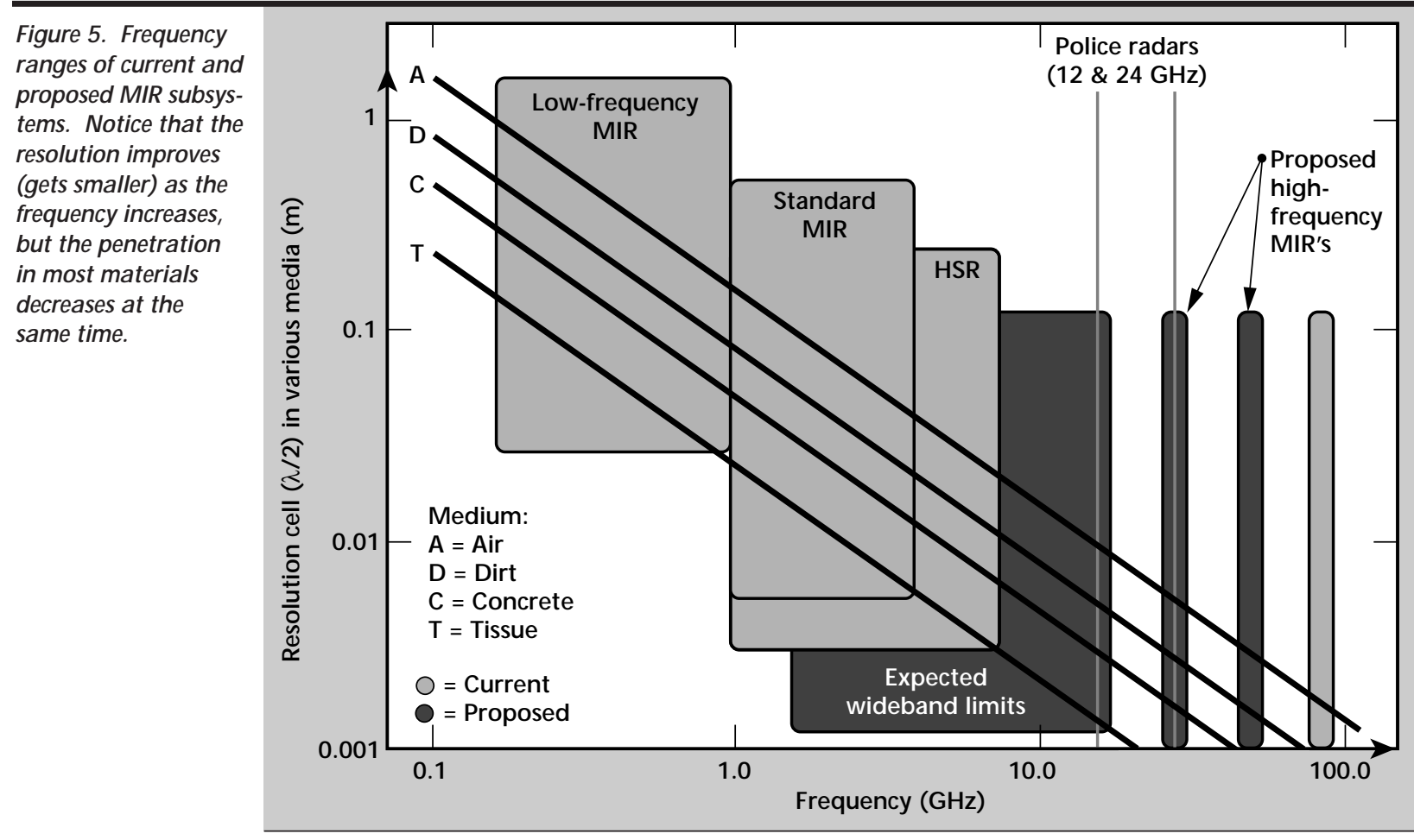


current MIR operating frequency band. Reasonablysized millimeter-wave antennas, with improved gain and directivity can be produced to extend the range of MIR, and improve angular resolution and system portability. In addition, compact high-gain antennas will enhance the performance in some of the applications for which MIR sensors have already been proven. Examples of such millimeter-wave MIR applications include bullet/projectile tracking; highresolution target acquisition for tanks and other weapon systems; robotic collision avoidance; airport ground traffic surveillance/ tracking; automotive systems; high-resolution personnel imaging; radar aids for the blind; and NDE of composite materials.

A prototype impulse driven $94-\mathrm{GHz}$ radar has been assembled to gauge the operational capabilities of impulse-driven ultra-wideband millimeter-wave radars. The test system consists of a standard MIR backend timing and signal processing module that drives a high-speed IMPATT diode sampler. This diode oscillates for several cycles at $94 \mathrm{GHz}$ and drives a high-frequency transmit antenna. Return signals are measured with a similar sampler on the receiver side, and again attached to the MIR signal processing module. A plot of the resulting waveform is shown in Fig. 6 . Initial test data indicates a radar bandwidth of $>5 \mathrm{GHz}$ and transmit power $>10 \mathrm{~mW}$. Antennas used had a $-3 \mathrm{db}$ beam width of $10^{\circ}$. Tests indicate that a properly designed impulse driven $94-\mathrm{GHz}$ radar should have a transmit power $>25 \mathrm{~mW}$ and a bandwidth $>15 \mathrm{GHz}$.

With additional development it may be possible to reach full waveguide bandwidth of $35 \mathrm{GHz}$ (75 to $110 \mathrm{GHz}$ ). Radar repetition rates from $\mathrm{kHz}$ to $>10 \mathrm{MHz}$ are easily reached. Proper design of IMPATT diode matching networks for the input-driven impulse and RF output matching could allow IMPATT diodes to be used to create radars in the 1 to $40 \mathrm{GHz}$ band with bandwidths on the order of 10 to $20 \mathrm{GHz}$. Further work needs to be done to better quantify the full capability of impulse-driven millimeter-wave IMPATT diodes.

\section{Single-antenna Systems}

The early MIR systems all had two antennas, one for transmit and one for receive. In this last year, we have performed work on single-antenna systems that use the same antenna for both functions. For example, a type of motion sensor we call the Field Disturbance Sensor (FDS) has been developed with 2- and 4-GHz pulsed-oscillators. The FDS is a range-gated homodyne motion sensor with similar characteristics to the MIR, yet only a single antenna is needed, and that antenna can be a standard directional one rather than omni-directional.

The Rangefinder can also be used in a singleantenna configuration by means of another recently developed "directional sampler" circuit. To receive while still transmitting, a method is needed to cancel the transmit pulse at the sampler (receiver) input. In the directional sampler, the transmit pulse is applied to the top of a resistive bridge. The transmit pulse is divided equally by the bridge resistors and applied to a differential sampler comprised of a pair of charge-holding capacitors and diodes. The output of the differential sampler is applied to an amplifier where, properly tuned, the sampled transmit pulse is differenced to zero.

\section{Future Work}

We envision many additional refinements for the MIR systems of the future. Many of those are centered around insights gained from government and commercial interactions. Most applications also require some level of effort, such as a change in range/sensitivity/directionality, or size/power/penetration, or pulse shape, or signal processing, to reduce it to practice. As proprietors of the MIR technology, we anticipate performing much of the "proof-of-principle" development work, while attracting private industry participation for mass production.

For FY-97, we plan to continue our progress toward higher frequencies and more modular systems. In this way, we can continue our efforts to characterize MIR systems and tailor them more

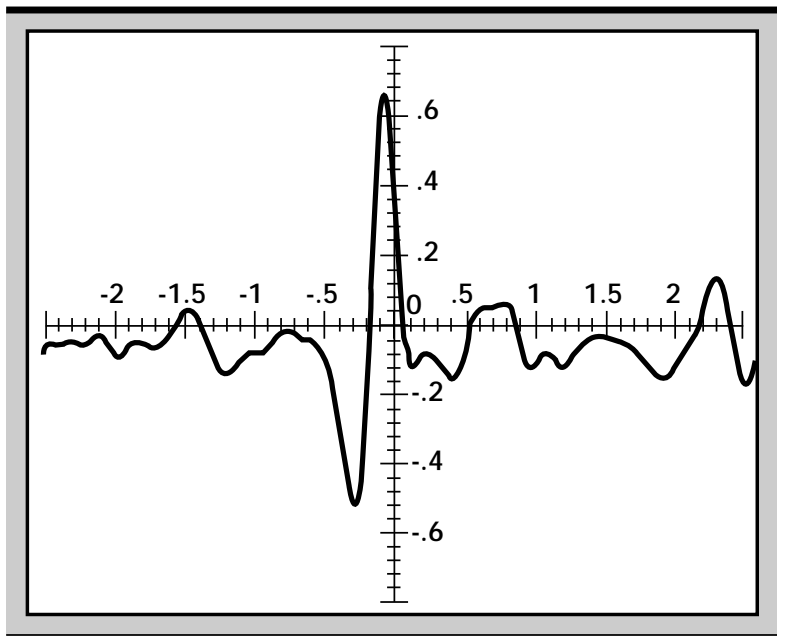

Figure 6. Pulsed 94-GHz received waveform from a metal plate at $1.32 \mathrm{~m}$ from the transmit/receive horns. The $94-\mathrm{GHz}$ signal is sampled by the MIR back-end and shifted to the 1 to $4 \mathrm{GHz}$ range. 
easily to the applications at hand. There is still significant $R \& D$ needed to have reliable turn-key high-frequency MIR systems. For example, we have long considered the possibility of integrating much of the back-end MIR circuitry into a single silicon ASIC. This is still expected soon, but we will most likely carry this out in conjunction with industrial partners. While our licensees and partners are continuing to develop commercial applications of $M I R$, our internal efforts must stay focused on the longer-term systems issues that will take us to the next step.

\section{Acknowledgments}

The authors would like to acknowledge the contributions of the scientists, engineers, and technicians involved with the MIR Project. These include J. Brase, R. Cavitt, G. Dallum, L. Haddad, R. Hugenberger, B. J ohnston, H. J ones, J. Mast, D. Mullenhoff, S. Nelson, T. Rosenbury, R. Stever, P. Welsh, and M. Wieting. Administrative help came from M. Mclnnis, C. Bothwell, M. Lynch, F. Reyna, R. Sachau, and S. Turner-Perry.

We also acknowledge the continued support from the Laser Programs Directorate ( $R$. Twogood, E. M. Campbell) and the Electronics Engineering Department.

\section{References}

1. Azevedo, S. G., T. E. McEwan, and J. P. Warhus (1996), "Microradar Development," Engineering Research, Development and Technology: Thrust Area Report, Lawrence Livermore National Laboratory, Livermore, Calif., (UCRL-53868-95), pp. 6-17.

2. Azevedo, S. G., and T. E. McEwan (1996), "Micropower Impulse Radar," Science and Technology Review, Lawrence Livermore National Laboratory, Livermore, Calif. (UCRL-52000-96-1/2).
3. McEwan, T. E. (1996), MIR Motion Sensor User's Guide, (Controlled Distribution), Lawrence Livermore National Laboratory, Livermore, Calif., (UCRL-MA124118).

4. McEwan, T. E. (1996), MIR Electronic Dipstick User's Guide, (Controlled Distribution), Lawrence Livermore National Laboratory, Livermore, Calif., (UCRL-MA124398).

5. McEwan, T. E. (1996), MIR Rangefinder User's Guide, (Controlled Distribution), Lawrence Livermore National Laboratory, Livermore, Calif., (UCRL-MA125056).

6. Azevedo, S. G., D. T. Gavel, J. E. Mast, E. T. Rosenbury, and J. P. Warhus (1996), "Arrays of Micropower Impulse Radar (MIR) Sensors for Subsurface Detection," Proceedings of the EUREL Conference on the Detection of Abandoned Land Mines, (IEE Conf.), Edinburgh, Scotland, United Kingdom, Pub. No. 431.

7. Mast, J. E., and E. M. J ohansson (1994), "Threedimensional ground penetrating radar imaging using multi-frequency diffraction tomography," Advanced Microwave and Millimeter Wave Detectors, (SPIE), Vol. 2275, pp. 25-26.

8. Azevedo, S. G., J. E. Mast, S. D. Nelson, E. T. Rosenbury, H. E. Jones, T. E. McEwan, D. J. Mullenhoff, R. E. Hugenberger, R. D. Stever, J. P. Warhus, and M. G. Wieting (1996), "HERMES: A high-speed radar imaging system for inspection of bridge decks," Nondestructive Evaluation Techniques for Aging Infrastructure and Manufacturing, (SPIE), Vol. 2946,(23) in press.

9. Gavel, D. T., J. E. Mast, J. Warhus, and S. G. Azevedo (1995), "An Impulse Radar Array for Detecting Landmines," Proceedings of the Autonomous Vehicles in Mine Countermeasures Symposium, Monterey, Calif., pp. 6-112.

10. Azevedo, S. G., D. T. Gavel, J. E. Mast, and J. P. Warhus (1995), "Landmine Detection and Imaging using Micropower Impulse Radar (MIR)," Proceedings of the Workshop on Anti-personnel Mine Detection and Removal, Lausanne, Switzerland, pp. 48-51. 


\title{
igh-Performance Insulator Structures for Accelerator Applications
}

\author{
Stephen E. Sampayan and David O. Trimble \\ Laser Engineering Division \\ Electronics Engineering
}

George J. Caporaso and Yu-Jiuan Chen

Inertial Confinement Fusion Program

Laser Programs

Clifford L. Holmes

Applied Research Engineering

Mechanical Engineering

Robert D. Stoddard and Ted F. Wieskamp

Defense Technologies Engineering Division

Mechanical Engineering

\author{
M. L. Krogh and S. C. Davis \\ Allied Signal Corporation \\ Kansas City, Missouri
}

It is experimentally observed that insulators composed of finely spaced alternating layers of dielectric $(<1 \mathrm{~mm})$ and thin metal sheets have substantially greater vacuum surface flashover capability than insulators made from a single uniform substrate. A conclusive theory that fully explains this effect has yet to be presented. The increased breakdown electric field that these structures exhibit may result either separately or in combination from 1) minimized secondary electron emission avalanche (SEEA) growth; 2) shielding of the insulator from the effects of charging; or 3) a modification of the statistical nature of the breakdown process by separating the structure into $\mathrm{N}-1$ additional sub-structures. We have previously performed measurements and reported on small- to moderatesized insulator structures. In the previous work we showed these structures to sustain electric fields 1.5 to 4 times that of a similar conventional single substrate insulator. In addition, we previously reported on the capability of these structures under various pulsed conditions, in the presence of a cathode and electron beam, and under the influence of intense optical illumination. In this paper we describe our on-going studies investigating the degradation of the breakdown electric field resulting from alternate fabrication techniques, the effect of gas pressure, and the effect of the insulator-toelectrode interface gap spacing. Additionally, we report on initial testing that subjects the insulator to the effect of energetic radiation fields.

\section{Introduction}

A U.S. patent is pending for this work.

We have pursued the development of compact, high-current ( $>2 \mathrm{kA}$ ), high-gradient accelerator systems for various Department of Energy missions over the past several years. This work has mainly focused on a new high-gradient, prompt pulse (on the order of 10 to $50 \mathrm{~ns}$ ) accelerator concept called the Dielectric Wall Accelerator (DWA). ${ }^{1}$ The pulsed electric field in this accelerator is developed by a series of asymmetric Blumleins incorporated into the insulator structure (Fig. 1). When this structure is combined with the new high-gradient 
vacuum insulator technology reported here, shortpulse high gradients of greater than 20 to $30 \mathrm{MV} / \mathrm{m}$ may be possible. ${ }^{2,3}$

The asymmetric Blumlein functions as follows. Two stacked pulse-forming lines, form the asymmetric Blumlein each with a different transit time and ideally, equal impedance. In the ideal configuration, these Blumleins consist of alternating layers of two dissimilar dielectric materials with permitivities, $\varepsilon_{r}$, which differ by a ratio of 9:1.

When the conductor in common with both lines is charged to potential, $\mathrm{V}_{0}$, and shorted on the circumference of the accelerator structure, two reversed polarity wavefronts move at a velocity proportional to $\varepsilon_{r}{ }^{-0.5}$ toward the beam tube.

For a fast pulse line length of time, $t$, and a slow pulse line length of time, $3 \mathrm{t}$, an energy gain of $2 \mathrm{~V}_{0}$ occurs across a single Blumlein structure into a matched beam load over the interval t to $3 t$.

The maximum gradient of this accelerator is defined by the dielectric strength of the wall dielectrics and the maximum pulsed surface breakdown electric field capability of the interior vacuum interface in the acceleration region. Most dielectric materials can support the required gradients; the vacuum insulator structures generally do not. To maximize these gradients, we have undertaken to improve the overall performance of vacuum insulators.

In addition to this particular accelerator application, we are pursuing other near-term applications. These include the Advanced Hydrotest Linear

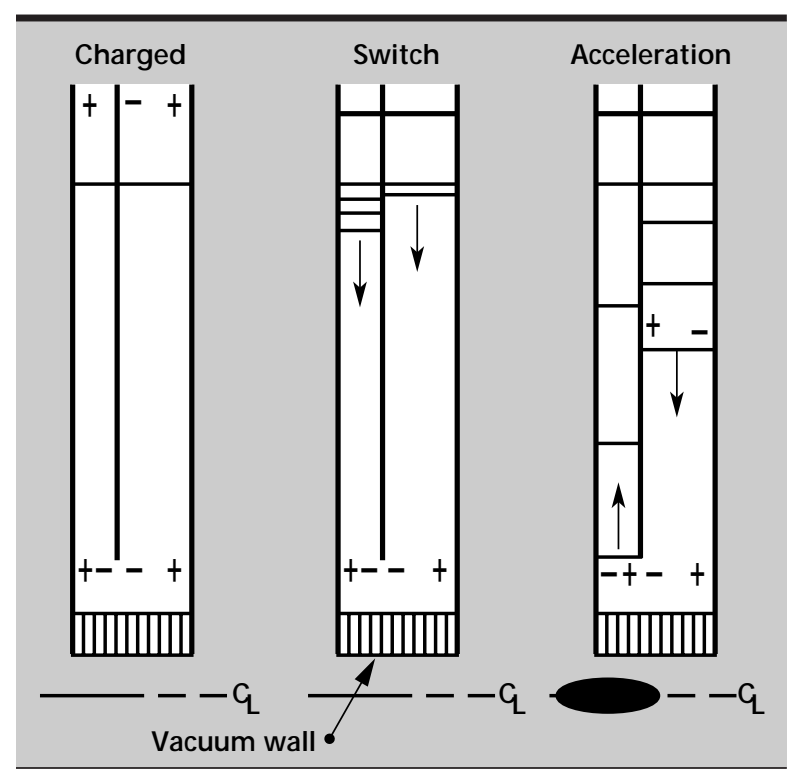

Figure 1. Principle of the asymmetric Blumlein in the Dielectric Wall Accelerator.
Induction Accelerator (AHF-LIA) proposed by Lawrence Livermore National Laboratory, and the Dual Axis Radiography Hydrotest (DARHT) Accelerator presently being built at Los Alamos National Laboratory. In these accelerators, highperformance insulators will be required to optimize accelerator gap design for long pulses (on the order of $2 \mu \mathrm{s}$ ) on the AHF-LIA system and also for multi-pulse options being considered for the DARHT system.

A high-gradient insulator consists of a series of very thin $(<1 \mathrm{~mm})$ stacked laminations interleaved with conductive planes. This insulator technology was originally conceived and disclosed by Gray in the early 1980 's ${ }^{4}$ and resulted from experimental observations that the threshold electric field for surface flashover increases with deceased insulator length (Fig. 2).5,6 Further investigations showed substantial increases in the breakdown threshold of these insulator structures over conventional, single substrate insulators. ${ }^{2}$ More recent data shows an increase of 1.5 to 4.0 times that over conventional insulator technology. ${ }^{3}$ We have also explored the properties of these structures in the context of switching applications, investigating their behavior under high-fluence photon bombardment. ${ }^{7}$

A certain amount of understanding of the increased breakdown threshold of these structures can be realized from the basic model of surface flashover. The most simplified vacuum surface breakdown model suggests that electrons originating from the cathode-insulator junction are

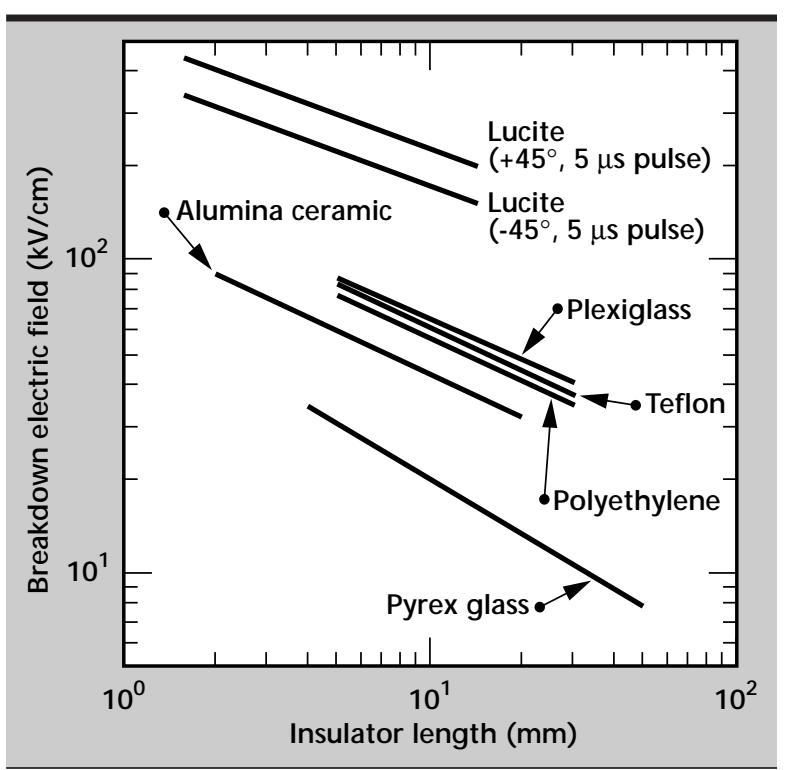

Figure 2. The effect of length scaling on the surface breakdown electric field of vacuum insulators. 
responsible for initiating the failure. ${ }^{8}$ When these electrons are intercepted by the insulator, additional electrons, based on the secondary emission coefficient of the surface, are liberated.

This effect leaves a net positive charge on the insulator surface, attracting more electrons and leading to escalation of the effect or SEEA breakdown.

It has been shown that full evolution of the discharge occurs within $0.5 \mathrm{~mm} .^{9}$ Thus, placing slightly protruding metallic structures at an equivalent interval is believed to interrupt the SEEA process and allow the insulator to achieve higher gradients before failure. Alternate modifications to this explanation include the effects of insulator shielding and equilibration of the induced surface charge. As a result, electron impact on the surface is modified. Or, alternately, by separation of the insulator into N-1 additional decoupled substructures, a local breakdown on the insulator cannot propagate to the remainder of the structure.

In this paper we describe our on-going work in which we have performed additional studies on the effect of various fabrication techniques, the effect of gas pressure, and the effect of the insulator-toelectrode interface spacing. Additionally, we report on initial testing which subjects the insulator to energetic radiation fields.

\section{Progress}

Small sample testing (approximately $2.5 \mathrm{~cm}$ diameter by $0.5 \mathrm{~cm}$ thick) was performed in a turbomolecular pumped, stainless-steel chamber at approximately $10^{-6}$ Torr. High voltage was developed with a $10 \mathrm{~J}$ "mini-Marx." The Marx developed a pulsed voltage of approximately 1 to $10 \mu$ s (baseto-base) and up to $250 \mathrm{kV}$ amplitude across the sample. Diagnostics consisted of an electric field sensor and a current viewing resistor. Failure of the insulator was determined by a prompt increase in Marx current and a prompt collapse in the voltage across the sample.

Several small sample insulators were fabricated by interleaving layers of $0.25-\mathrm{mm}$ fused silica, formed by depositing gold on each planar insulator surface by a sputtering technique and then bonding the stacked layers by heating while applying pressure. Bond strength between the gold layer and substrate using this technique was measured to exceed $10 \mathrm{kpsi}$. To perform the breakdown experiments, the structure was slightly compressed between highly polished bare aluminum electrodes that establish the electric field for the tests.
To obtain a particular data set, the insulators were subjected to several low-voltage conditioning pulses. The voltage was then increased a small amount incrementally until breakdown occurred. Voltage was reduced for several shots and then incrementally increased again until a constant value was achieved. In these experiments, however, we generally observed that the insulators did not condition. Once a breakdown occurred at a particular field, reducing the voltage slightly and increasing it again did not cause an increase in breakdown field.

To produce a given data set we applied up to 150 to 200 shots to a given structure and attempted to determine if any damage to the structure occurred that significantly altered the breakdown characteristics. At these applied energies, we generally did not observe any degradation. These data were then reduced to reliability plots by determining the total number of successful shots over the total number of applied shots. In these data we define the electric field as the applied voltage divided by the total insulator length. We define reliability at a given electric field as the total number of successful shots over the total number of shots.

Using this method, we observed flashover of the small samples at approximately $175 \mathrm{kV} / \mathrm{cm}$ for the fused silica substrates (Fig. 3). The effect of pulse width from 1 to $10 \mu \mathrm{s}$ on this breakdown threshold was well within the statistical nature of our data. The trend in conventional insulator technology (Fig. 4) for $0^{\circ}$-insulators indicates a breakdown threshold of approximately $50 \mathrm{kV} / \mathrm{cm}$. Thus, with

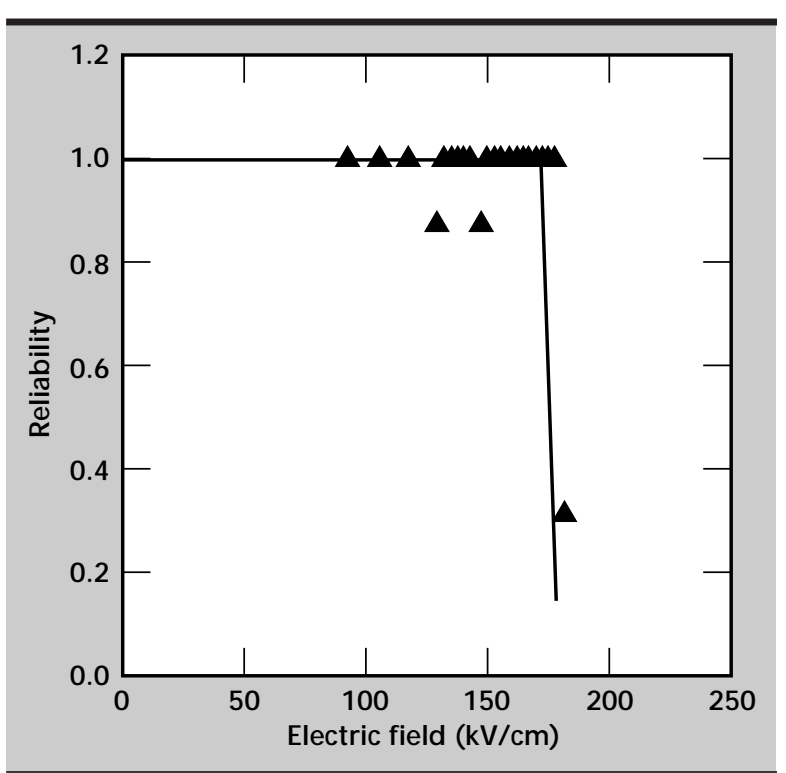

Figure 3. Pulsed surface breakdown reliability of a groundfused silica high-gradient insulator. 
these insulators there was a net increase in the performance over conventional technology by a factor of approximately 3.5 .

To ensure concentricity on these first structures, a finish grinding operation was performed on the outside diameter. Since this process is a timeconsuming second operation, an alternate fabrication means was pursued. To simplify fabrication, we attempted an ultrasonic machining process. Although it was possible to fabricate the part in a

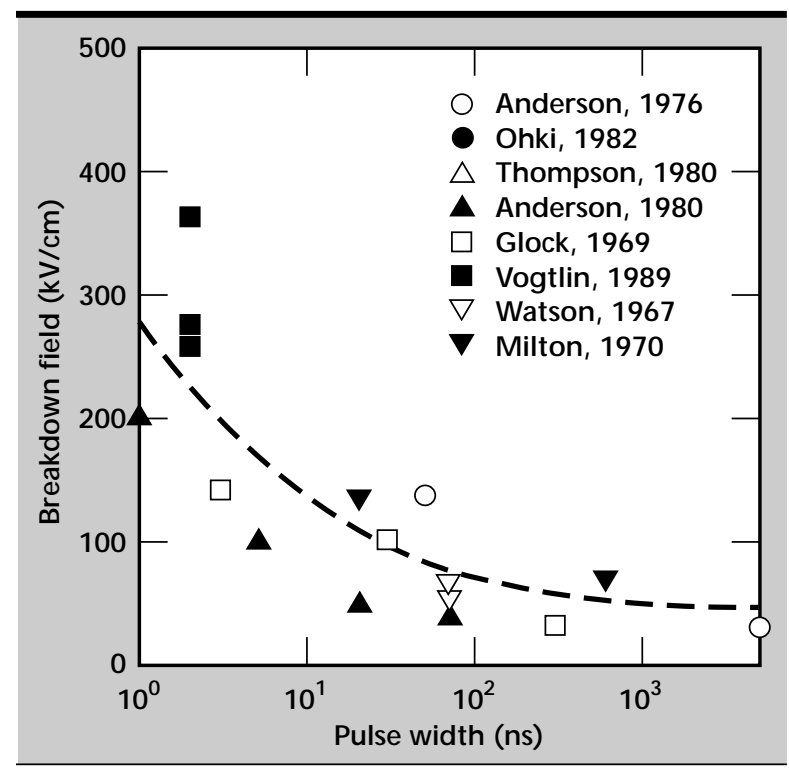

Figure 4. Pulsed surface breakdown electric field as a function of pulse width for single substrate, straight wall insulators.

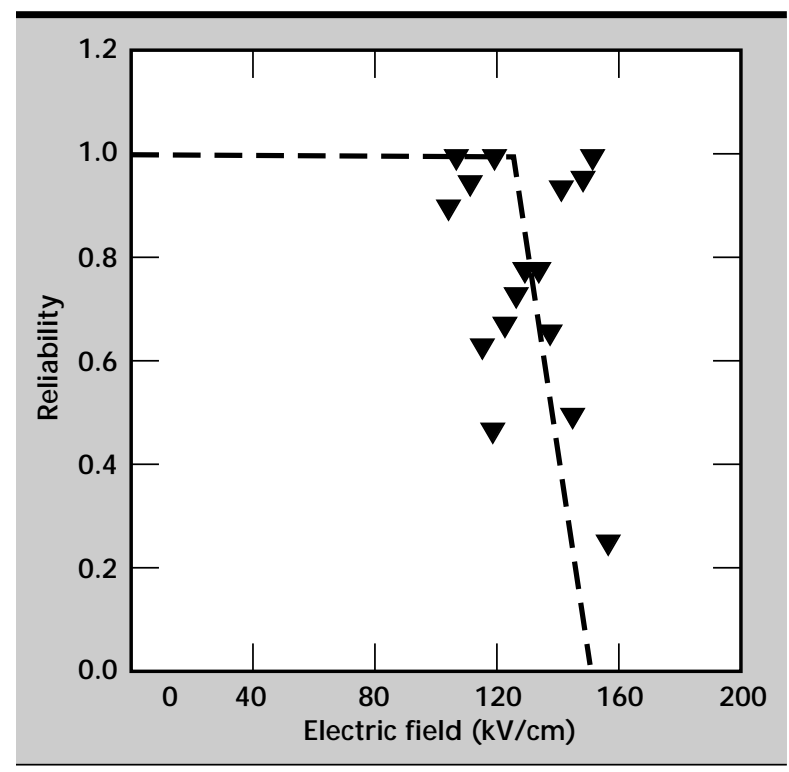

Figure 5. Pulsed surface breakdown reliability of a fused silica high-gradient insulator fabricated using an ultrasonic fabrication technique. single operation, the surface was left slightly rougher. Comparison of the breakdown characteristics of these samples showed significantly more scatter and on average a slightly decreased breakdown threshold of approximately 25\% (Fig. 5).

The structures were also subjected to increased pressures to determine susceptibility to breakdown (Fig. 6). In these data, using the previously described procedure, a fixed reliability was established at the various pressures. All data was then

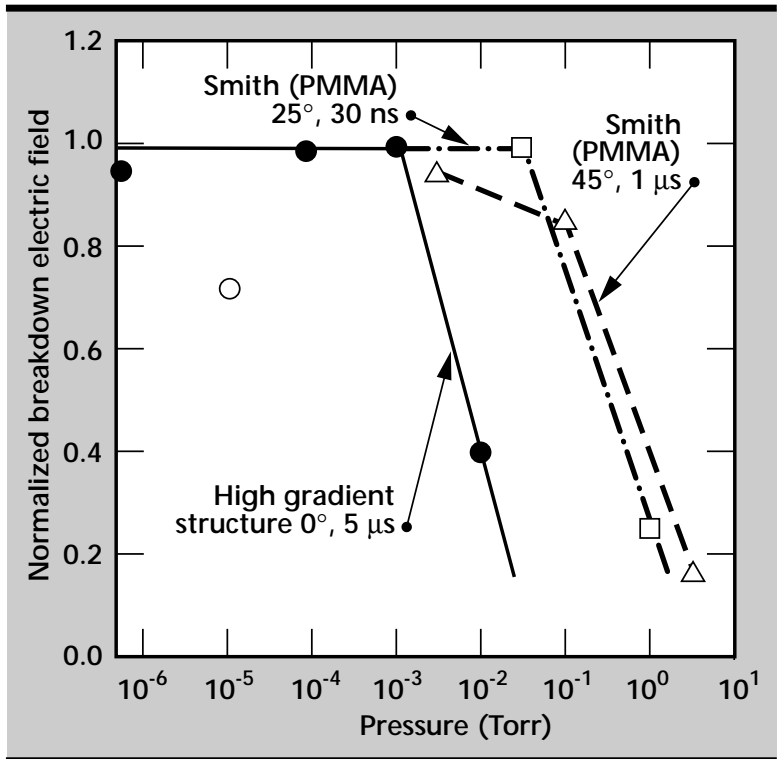

Figure 6. Effect of gas pressure on the performance of highgradient insulators.

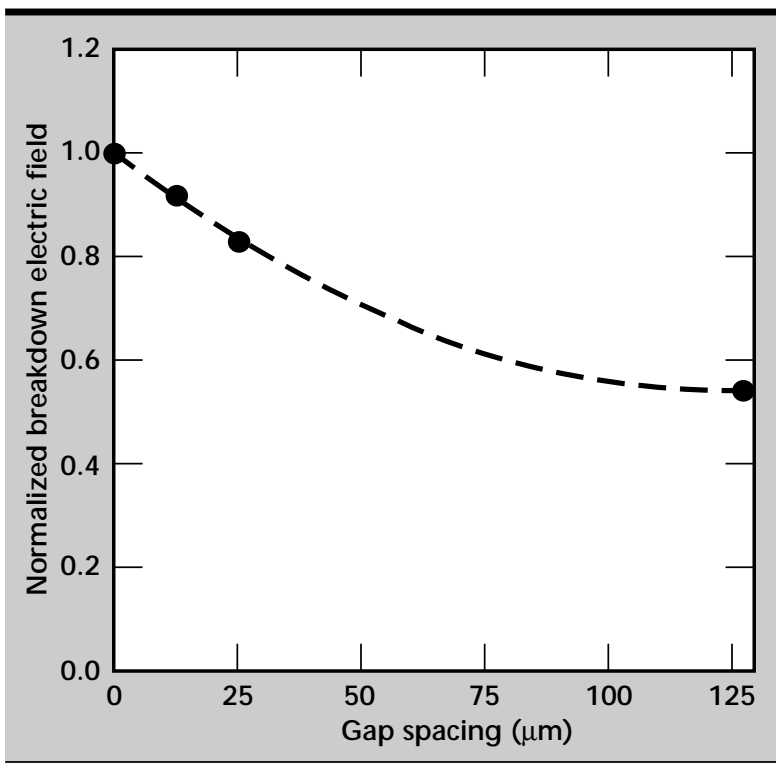

Figure 7. Effect of an increased electrode/insulator interface gap. 
normalized to a mean breakdown electric field. Susceptibility to breakdown stays relatively constant up to about the $10^{-3}$ Torr range, at which point, the field at which breakdown occurs decreases rapidly. Also shown are data from previous work by Smith. ${ }^{10}$ It appears that the new structures show a lower breakdown electric field threshold than that of the previous data.

Any insulator not in full contact with the electrode surface will show a higher susceptibility to breakdown and lower reliability at a given electric field. This effect results from the enhanced electric field that occurs between the insulator/electrode interface gap. To investigate this effect with these new structures, shims were placed between the cathode electrode and insulator, and the reliability at a given electric field were determined. This data, normalized to the configuration where the insulator was flush with the electrode, is shown Fig. 7. In these tests, we observed the reduction in the capability of the insulator to be strongly reduced from about $90 \%$ of full capability for a $12-\mu \mathrm{m}$ interface gap to less than $60 \%$ for a $125-\mu \mathrm{m}$ interface gap.

We have also begun testing these structures in the presence of an ion beam and various other radiation fields. In this test, we used a high-current pulsed-ion source. The ions are allowed to impinge on the structures near the cathode triple junction while a high potential is applied across the sample. Our observations to date are somewhat qualitative and indicate that the ion beam does not induce an immediate and prompt breakdown on impact. Rather, we observe only a somewhat reduced breakdown electric field capability resulting from direct ion impact on the insulator surface.

\section{References}

1. Caporaso, G. (1994), "Induction LINACS and Pulsed Power," Frontiers of Accelerator Technology, Proc. 1994 J oint Topical Course, Maui, HI.

2. Elizondo, J., and A. Rodriguez (1992), "Novel High Voltage Vacuum Surface Flashover Insulator Technology," Proceedings of 1992 15th International Symposium on Discharges and Electrical Insulation in Vacuum, Vde-Verlag Gmbh, Berlin, Germany, pp. 198-202.

3. Sampayan, S., G. Caporaso, Y. Chen, C. Holmes, E. Lauer, D. Trimble, B. Carder, J. Elizondo, M. Krogh, B. Rosenblum, C. Eichenberger, and J. Fockler, "High Gradient Insulator Technology for the Dielectric Wall Accelerator," (1995), Proceedings of the 1995 Particle Accelerator Conference, (IEEE), New York, N.Y., pp.1269-1271.

4. Gray, E., (1984), private communication.

5. Milton, O. (1972), "Pulsed Flashover of Insulators in Vacuum," IEEE Trans. Electr. Insul., Vol. El-7, pp. 9-15.

6. Pillai, A. S., and R. Hackam (1982), "Surface Flashover of Solid Dielectric in Vacuum," J. Appl. Phys., Vol. 53(4), pp. 2983-2987.

7. Sampayan, S., G. Caporaso, M. Norton, D. Trimble, B. Carder, and J. Elizondo, "Optically Induced Surface Flashover Switching for the Dielectric Wall Accelerator," (1995) Proceedings of the 1995 Particle Accelerator Conference, (IEEE), New York, N.Y., pp. 2123-2125.

8. Miller, H. C. (1988), "Surface Flashover of Insulators," G. E. Aerospace Report, (GEPP-TIS1064-UC-13).

9. Glock, W., and S. Linke (1969), "Pulsed High-Voltage Flashover of Vacuum Dielectric Interfaces," Cornell University Report, Laboratory of Plasma Studies, Ithaca, N.Y., (No. LPS 24).

10. Smith, I. D. "Pulsed Breakdown of Insulator Surfaces in Poor Vacuum," unpublished AWRE report, Aldermaston, United Kingdom. 



\title{
ompact Gas Switch Development
}

\author{
David A. Goerz, Michael J. Wilson, and Ronnie D. Speer \\ Defense Sciences Engineering Division \\ Electronics Engineering
}

\author{
Joseph P. Penland \\ Defense Technologies Engineering Division \\ Mechanical Engineering
}

We have developed a low-profile, high-voltage, spark-gap switch designed to be closely coupled with other components into an integrated high-energy pulsed-power source. We performed field modeling to determine the appropriate shape for the highly stressed insulator and electrodes, and employed special manufacturing techniques to mitigate the usual mechanisms that induce breakdown and failure in solid dielectrics. We have constructed and tested a prototype switch unit and achieved satisfactory operation at $100 \mathrm{kV}$ levels. Preliminary tests to evaluate repetitive operation and lifetime have been encouraging.

\section{Introduction}

Spark-gap switches are commonly used in Marx generators and other high-energy pulsed-power sources. This type of switch consists of two metal electrodes, separated by a gap filled with pressurized gas contained within a dielectric housing. The switch operates when the electric field in the gap exceeds the breakdown level of the gas, or when charge carriers are introduced into the gap by some external means.

A Marx generator uses a fundamental circuit that charges many capacitors in parallel, then switches them into a series configuration to generate a highvoltage output equal to the sum of the voltages across each capacitor. In principle, Marx generators are simple, and their capability is largely determined by the basic capacitors and switches that make up each stage. In practice, the performance of Marx generators depends critically on physical layout and construction details.

In most applications, Marx generators are constructed with standard, commercially available components that are arranged in an orderly manner into compact assemblies. Since these components are made for general use, their packaging and terminal styles are usually less than optimal for achieving maximum performance and the compactness needed for some applications. Significant improvements can be realized by modifying standard components or by manufacturing special components to fit into integrated packages.

We have developed a design for a repetitivelyswitched, Marx-type high-voltage generator based on custom components that can be closely coupled and integrated into an extremely compact assembly. This ultra-compact Marx (UCM) can be used in a variety of special applications requiring a compact high-voltage pulsed-power source. The concept relies on a low-profile, low-inductance, high-voltage, spark-gap switch with the following performance levels:

Hold-off voltage: $100 \mathrm{kV}$

Peak current: $30 \mathrm{kA}$

Repetition rate: $10 \mathrm{~Hz}$

Charge transfer: $0.1 \mathrm{C}$

Inductance: $5 \mathrm{nH}$

Capacitance: $130 \mathrm{pF}$

\section{Progress}

We have evaluated many design options and performed field modeling to evaluate the electrical stresses and quantify field enhancements of different shaped assemblies. Through an iterative process, we have been able to identify the limiting features 
and devise suitable design and construction methods to satisfy the basic requirements. Figure $1 \mathrm{la}$ is a sketch of the compact gas switch.

The shape of the metallic and dielectric parts is crucial to properly manage the electric fields and keep the stresses below the threshold for flashover or breakdown of a material. Figures $\mathbf{1 b}$ and $\mathbf{1 c}$ show field modeling results where contours of equipotential lines are plotted. The metal electrodes and insulator surfaces are appropriately shaped to reduce electric field stresses in the weakest regions where dissimilar materials meet, and to spread the fields evenly throughout the dielectric materials, allowing them to operate closer to their intrinsic breakdown levels.

Figure $\mathbf{1 b}$ shows that for the chosen dimensions with an applied voltage of $100 \mathrm{kV}$, the electrical field is less than $30 \mathrm{kV} / \mathrm{cm}$ at the triple-point region where the metal, plastic, and gas all meet, and the field is less than $130 \mathrm{kV} / \mathrm{cm}$ along the envelope of plastic material containing the pressurized gas. These stress levels are below the thresholds reported by others as troublesome. ${ }^{1,2}$

The average field across the thinnest annular region of plastic is $500 \mathrm{kV} / \mathrm{cm}$, whereas the highest field at the outermost enhanced region is $575 \mathrm{kV} / \mathrm{cm}$.
The gap between the cathode and anode electrodes is sized according to the desired operating level and gas pressure for a particular gas species or mixture. A nominal gap of $2.0 \mathrm{~mm}$ will normally breakdown at $100 \mathrm{kV}$ with $\mathrm{SF}_{6}$ pressurized to 100 psia. Field modeling allowed us to correct the empirical relationship for gas breakdown of planar gaps by including the effect of field enhancement at the edges. As evident in Fig. 1b, the fields are enhanced along the surface of the electrodes, reaching $560 \mathrm{kV} / \mathrm{cm}$. This is described as an enhancement factor ( $f *)$ of 1.120 , given by the ratio of $560 \mathrm{kV} / \mathrm{cm}$ to $500 \mathrm{kV} / \mathrm{cm}^{3}$

We constructed a special test fixture to evaluate various switches and demonstrate their performance over the desired range of operating parameters.

Figure $\mathbf{2 a}$ is a photograph of the assembled unit next to a high-voltage probe used to monitor the charge voltage. The slotted metal cylinder is the outer current return path for performing current ringdown tests. The finned cylindrical structure below the test fixture is a high-energy current-viewing resistor used as a diagnostic. Figure $\mathbf{2} \mathbf{b}$ is a sketch of the cross-section of the test fixture showing a 1-cm-thick switch body nestled between a ring of ceramic capacitors on top and a metal spacer below, with channels for flowing gas through the switch electrodes.

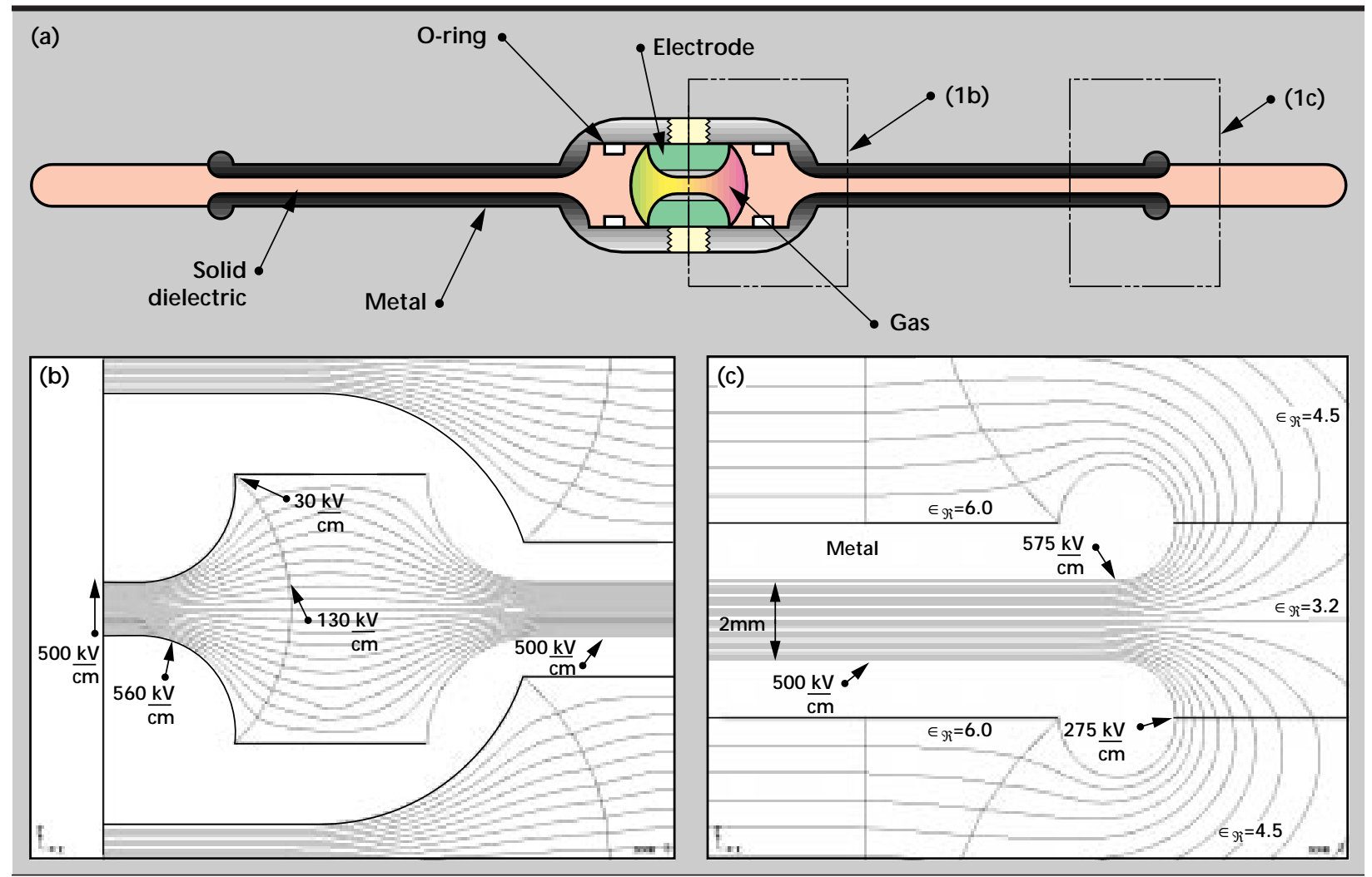

Figure 1. (a) Schematic of compact gas switch; (b) and (c) show field modeling results. 


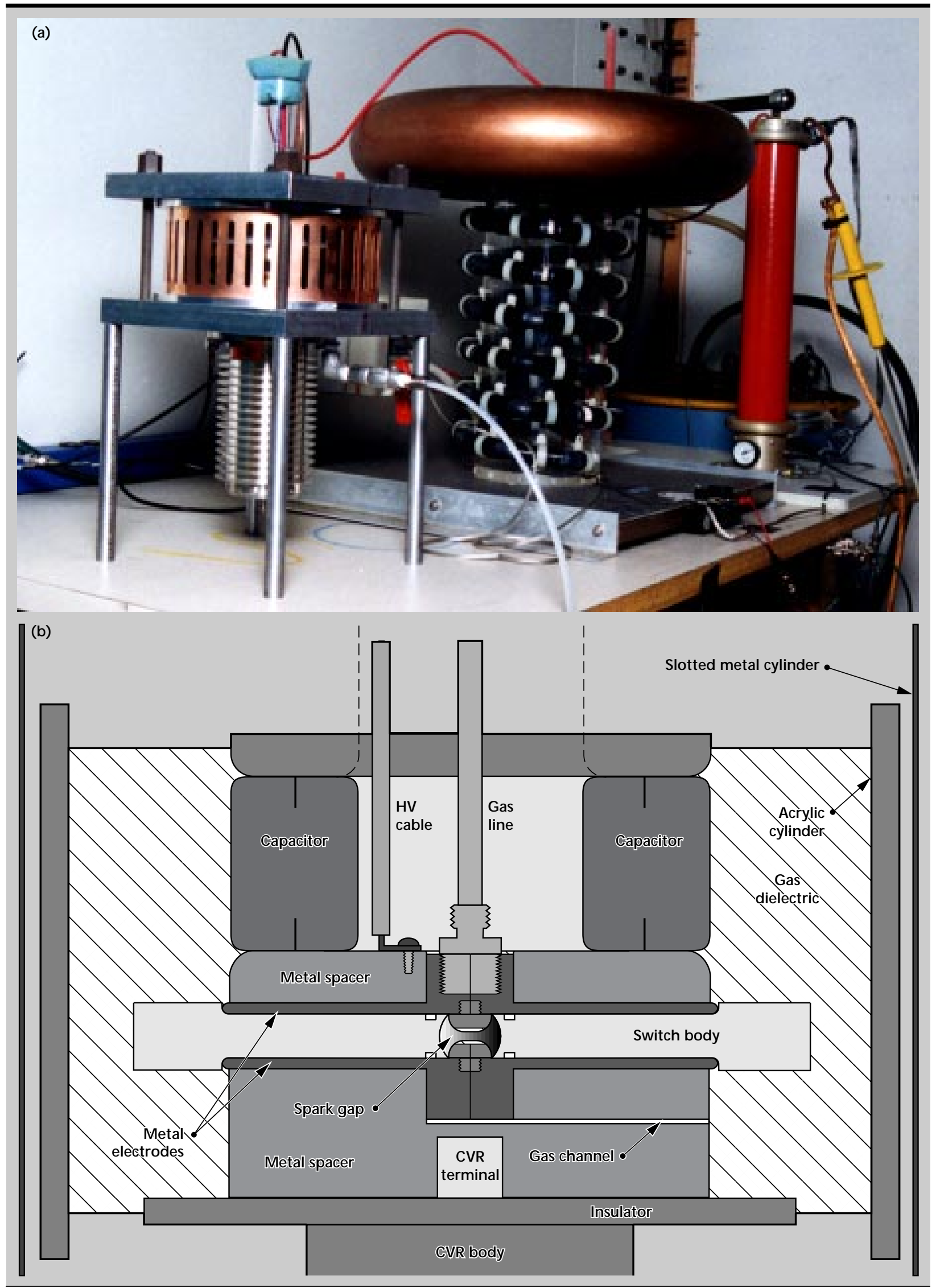

Figure 2. (a) Photograph of apparatus; (b) sketch of cross-section of test fixture. 
Three different sets of electrodes were used to characterize the switch with nominal gap spacings of $2.0,2.5$, and $3.0 \mathrm{~mm}$. Figure 3 shows results from testing the static breakdown performance of the compact gas switch. The solid markers represent the breakdown measurements that were made at each pressure increment of $5 \mathrm{psi}$. The open markers represent the well-known relationship for breakdown in $\mathrm{SF}_{6}$ gas $^{3}$ corrected for the field enhancements for these particular shaped electrodes. While there is some statistical variation in the breakdown levels, the general agreement with the empirical model indicates that the switch does indeed function as intended. Considerable testing confirmed that the electric field stress has been properly managed at the triple points and along the insulator surface, and that the switch performs as expected.

Further testing was done to exercise the compact gas switch at expected peak currents and chargetransfer levels to determine whether the insulator would survive repetitive high-energy pulses, or whether electrode erosion would become troublesome. Figure 4 shows a typical voltage trace from a 4-s burst-mode operation of a 3-mm gap switch with $\mathrm{SF}_{6}$ at 65 psia and the $100-\mathrm{kV}$ power supply current limited by a $20-M \Omega$ series resistor. Figure 4 shows the current trace from the ringdown event. In this case the oscilloscope was set up to average the first 30 ringdown current waveforms.

This mode of operation was also used to determine the statistical variation of voltage breakdown levels to evaluate how well the switch would function

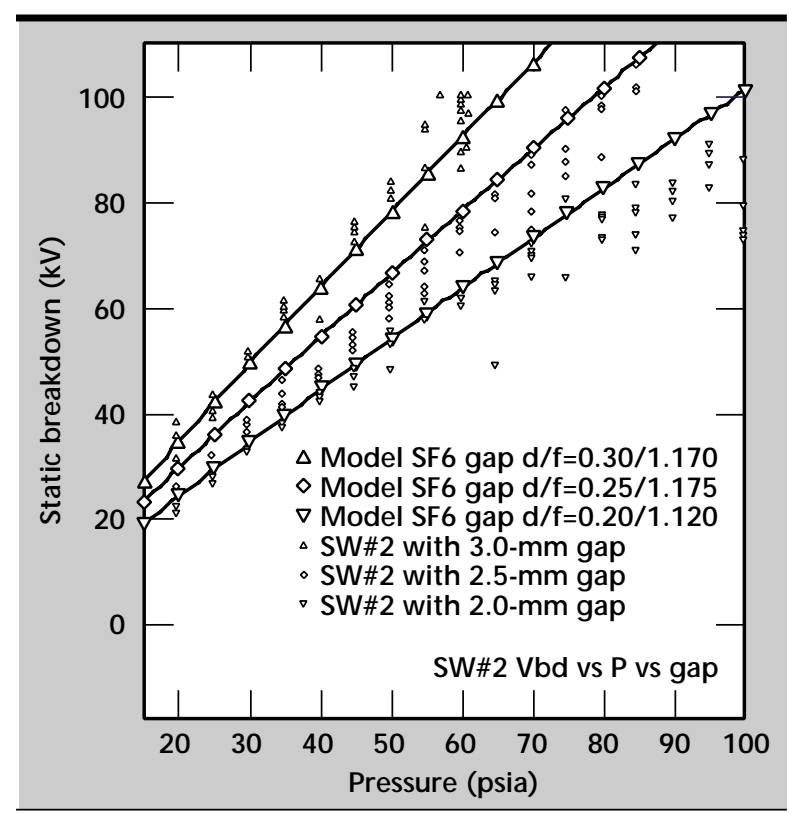

Figure 3. Test results from static breakdown performance on compact gas switch. in a Marx-type high-voltage generator. Figure $\mathbf{5}$ shows a histogram of the number of switch breakdowns versus voltage level. For this 4-s burst the mean operating voltage was $88.8 \mathrm{kV}$ and the standard deviation was $4.5 \mathrm{kV}$ or $5.0 \%$. This statistical variation is adequate for a Marx generator to function reliably with a reasonable amount of voltage coupling between stages to ensure successive switch operation.

To evaluate the expected lifetime of such a compact switch assembly, multiple 4-s bursts were taken, and the voltage and ringdown current waveforms were recorded for each shot. The switch still operated satisfactorily after more than 175 bursts, totaling more than 7000 individual shots. This series of tests was concluded when one of the capacitors

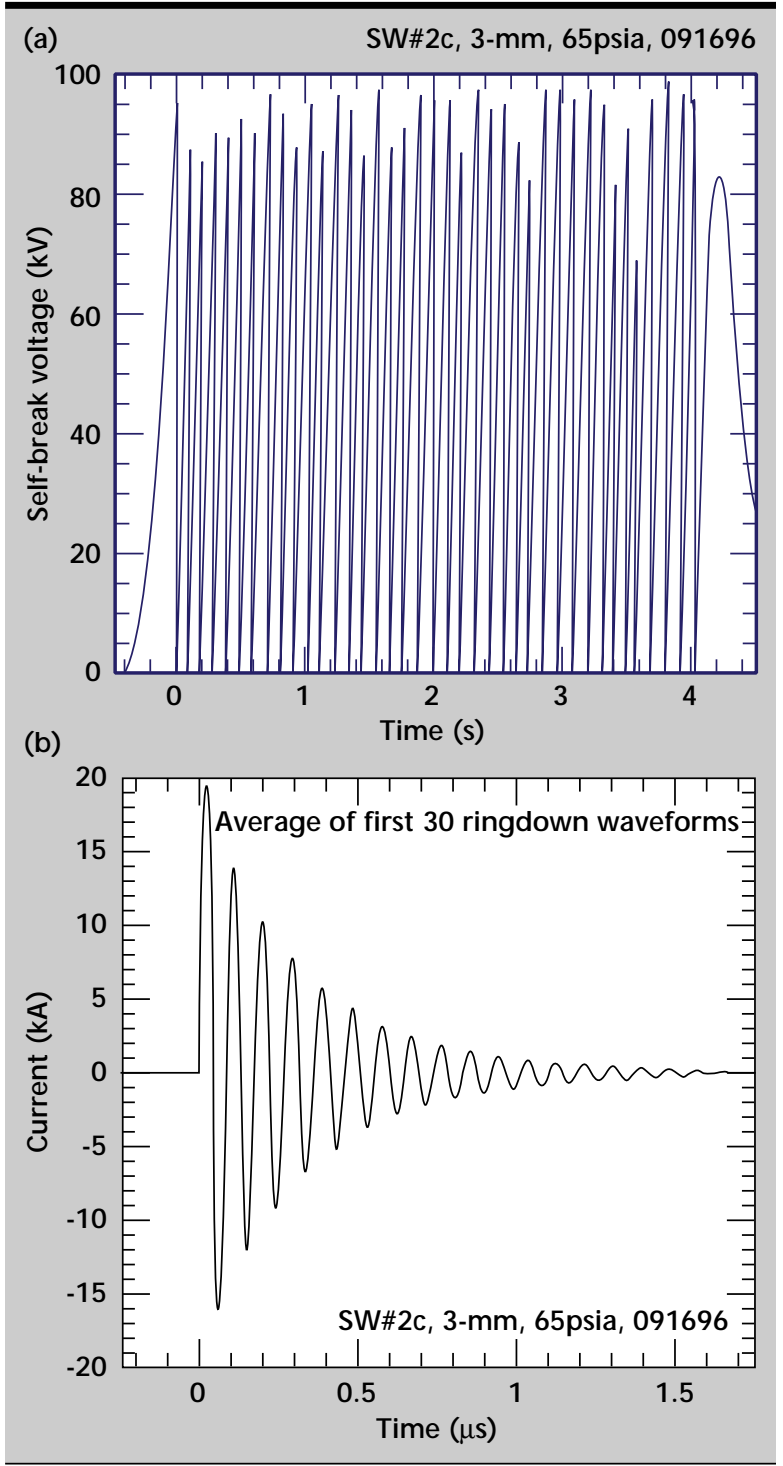

Figure 4. (a) Typical voltage trace; (b) current trace from ringdown event. 
failed. The switch was inspected and later reinstalled for further tests. Figure 6a shows a close-up photograph of the Lexan switch housing. No tracking or deterioration could be seen.

The anode and cathode button electrodes were weighed before and after the lifetime tests described above. The mass loss was $5.4 \mathrm{mg}$ for each electrode. The total charge transferred through the switch during the period in which these electrodes were installed was $30.4 \mathrm{C}$. The specific mass loss amounted to $0.178 \mathrm{mg} / \mathrm{C}$.

Several types of insulator materials were used to evaluate machining methods. Most of the electrical testing was done with a polycarbonate material (Lexan). Figure $\mathbf{6} \mathbf{b}$ shows a close-up photograph of one switch housing made from a large Lexan cylinder. Stress fractures were apparent after machining the inner switch cavity. This particular switch still operated satisfactorily for more than 1000 shots; however, the crazing became progressively worse. Switch housings were also manufactured using alumina-trihydrate (ATH) loaded epoxy and EPON-825 thermoset resin. ATH machined very easily, whereas some difficulty was experienced machining the EPON material.

\section{Future Work}

We plan to continue the development of the compact gas switch and demonstrate its performance in an ultra-compact, high-voltage Marx generator. More effort will go into evaluating higherstrength materials and developing advanced manufacturing methods for making intricately shaped parts.

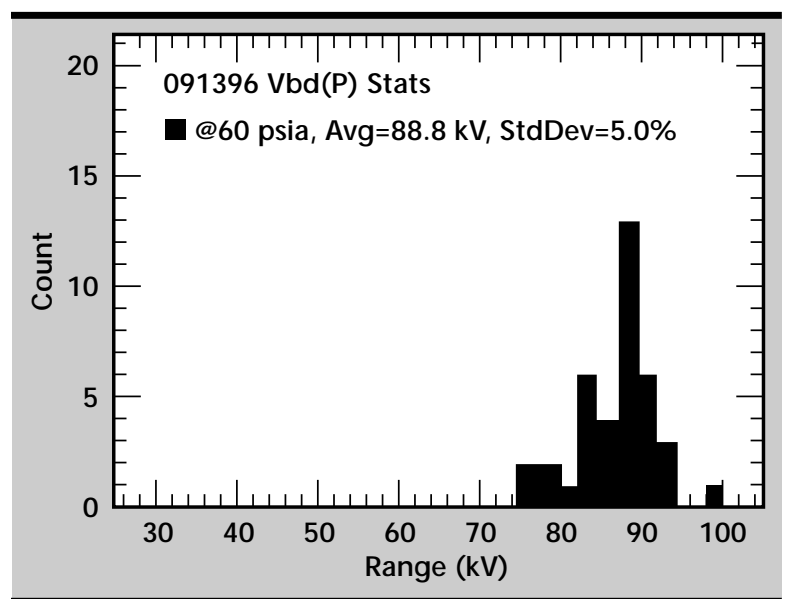

Figure 5. Histogram of switch breakdowns as a function of voltage level.
We will conduct further tests on the different materials and assemblies to fully characterize their performance levels. We anticipate a need to perform 3-D analysis of electric field enhancements to determine optimal shapes of parts and interconnections for an integrated Marx package.

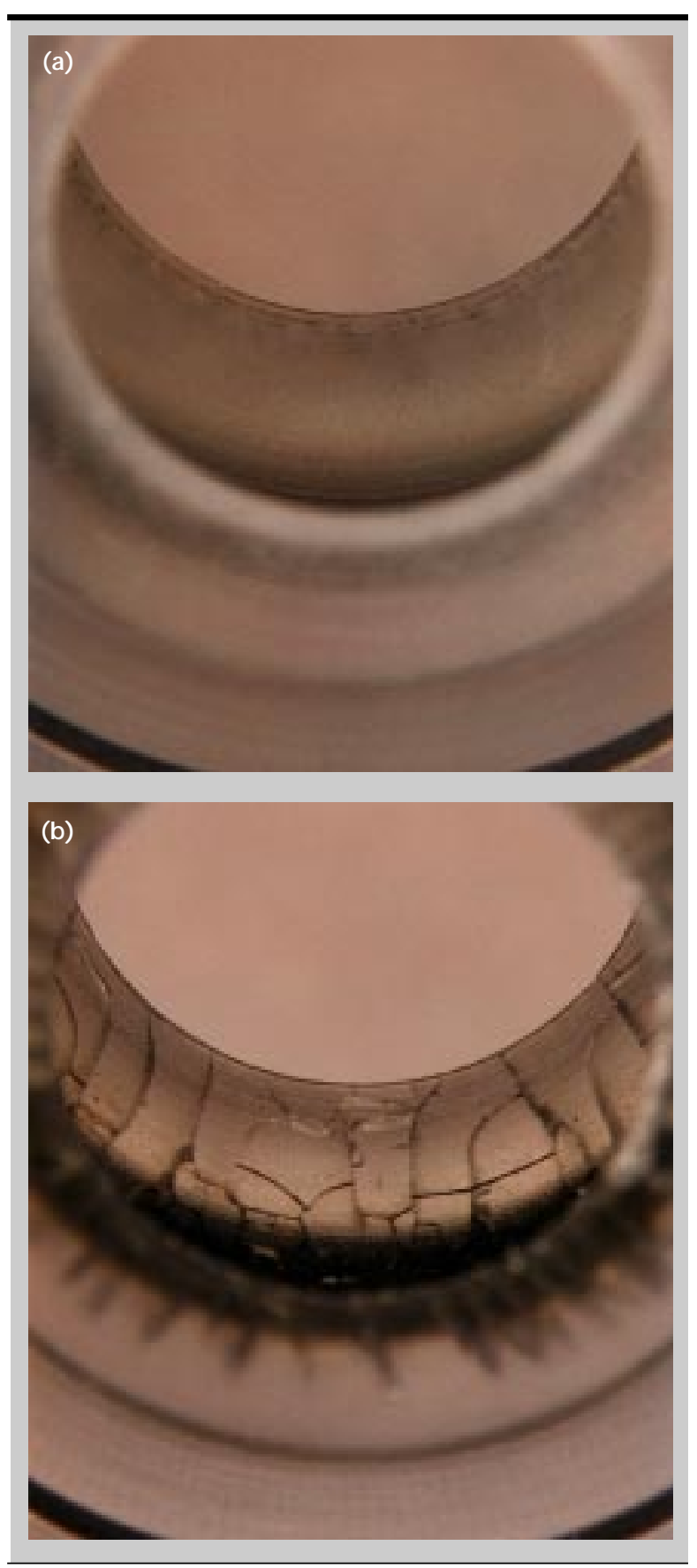

Figure 6. (a) Photograph of tested Lexan switch housing; (b) photograph of machined Lexan switch housing with stress fractures. 


\section{Acknowledgments}

The authors gratefully acknowledge the expertise and support of the Computational Electronics and Electromagnetics Thrust Area and the valuable contribution of $\mathrm{W}$. $\mathrm{Ng}$ who performed the field modeling.

\section{References}

1. Laghari, J. R. (1981), "Surface Flashover of Spacers In Compressed Gas Insulated Systems," IEEE Transactions on Electrical Insulation, Vol. EI-16 (5).

2. Laghari, J. R. (1985), "Spacer Flashover in Compressed Gases," IEEE Transactions on Electrical Insulation, Vol. El-20 (1).

3. Alston, L. L. (1968), "Breakdown Characteristics in Gases," High Voltage Technology, Oxford University Press, pp. 45-58. 

